\title{
The Sensible Heat Flux in the Course of the Year at Ny-Ålesund, Svalbard: Characteristics of Eddy Covariance Data and Corresponding Model Results
}

\author{
Georg Jocher, ${ }^{1,2}$ Alexander Schulz, ${ }^{1}$ Christoph Ritter, ${ }^{1}$ Roland Neuber, ${ }^{1}$ \\ Klaus Dethloff, ${ }^{1}$ and Thomas Foken ${ }^{3,4}$ \\ ${ }^{1}$ Alfred Wegener Institute for Polar and Marine Research, Telegrafenberg A43, 14473 Potsdam, Germany \\ ${ }^{2}$ Departement of Forest Ecology and Management, Swedish University of Agricultural Sciences, Skogsmarksgränd, 90183 Umeå, Sweden \\ ${ }^{3}$ Department of Micrometeorology, University of Bayreuth, Universitätsstraße 30, 95447 Bayreuth, Germany \\ ${ }^{4}$ Bayreuth Center of Ecology and Ecosystem Research (BayCEER), Dr. Hans-Frisch-Straße 1-3, 95448 Bayreuth, Germany
}

Correspondence should be addressed to Georg Jocher; georg.jocher@slu.se

Received 15 June 2014; Revised 14 August 2014; Accepted 26 August 2014

Academic Editor: Bala Subrahamanyam

Copyright @ 2015 Georg Jocher et al. This is an open access article distributed under the Creative Commons Attribution License, which permits unrestricted use, distribution, and reproduction in any medium, provided the original work is properly cited.

In this paper we present one year of meteorological and flux measurements obtained near Ny-Ålesund, Spitsbergen. Fluxes are derived by the eddy covariance method and by a hydrodynamic model approach (HMA) as well. Both methods are compared and analyzed with respect to season and mean wind direction. Concerning the wind field we find a clear distinction between 3 prevailing regimes (which have influence on the flux behavior) mainly caused by the topography at the measurement site. Concerning the fluxes we find a good agreement between the HMA and the eddy covariance method in cases of turbulent mixing in summer but deviations at stable conditions, when the HMA almost always shows negative fluxes. Part of the deviation is based on a dependence of HMA fluxes on friction velocity and the influence of the molecular boundary layer. Moreover, the flagging system of the eddy covariance software package TK3 is briefly revised. A new quality criterion for the use of fluxes obtained by the eddy covariance method, which is based on integral turbulence characteristics, is proposed.

\section{Introduction}

Climate in the Arctic is known to show stronger variability in surface temperature than elsewhere in the Northern hemisphere, a phenomenon which is called "Arctic amplification" $[1,2]$. Among other factors (as cloud-radiation or albedo feedback) also the vertical heat flux between ocean and atmosphere in retreating (or expanding) sea ice cover is thought to be one reason for this Arctic amplification [3,4]. Due to the large temperature differences the exchange of energy between the open ocean and/or leads and the cold Arctic atmosphere is much higher than the exchange of energy between a closed ice cover and the atmosphere.

Due to the complexity of feedback mechanisms within the Arctic atmosphere, especially within the Arctic atmospheric boundary layer, climate models show the largest deviations there [5]. More recently Medeiros et al. [6] analyzed inversion strengths in climate models and pointed out that they are frequently overestimated in models during stable conditions. Mäkiranta et al. [7] posed the question whether stability functions from Monin-Obukhov-similarity [8] in the presence of topographic disturbances of the Arctic atmospheric boundary layer are still usable and noted that models tend to underestimate turbulent mixing during stable conditions (see also, e.g., [9]). Hence, any local orographic disturbance which might alter the boundary layer and the turbulent fluxes within it is of concern when observations and models shall be compared. Eddy covariance measurements, nowadays a mature technology (e.g., [10]), have already been performed in the orographically challenging environment of $\mathrm{Ny}$-Ålesund $\left(\mathrm{N} 78^{\circ} 55.287^{\prime}, \mathrm{E} 011^{\circ} 54.851^{\prime}\right.$, e.g., [11-13]). Lüers and Bareiss [12] described shallow inversions occurring there 
and the need of careful interpretation of eddy covariance data, for example, during intermittent turbulence. In general disturbed near-surface temperature profiles are a prominent phenomenon in Arctic regions and these profiles have to be handled carefully, mainly regarding potential decoupling processes between the layer above and beyond a near-surface temperature maximum/minimum. Jocher et al. [11] found gravity waves and compared fluxes from two sites around the Kongsfjord region on Svalbard; Westermann et al. [13] described the annual cycle of turbulent fluxes presenting mean values of the turbulent fluxes during different seasons in the course of the year at the Bayelva site close to the village of $\mathrm{Ny}$-Ålesund. In this paper we want to go a step further inside and present the smaller scale special characteristics of the sensible heat flux in the course of the year near Ny-Ålesund, depending on the season and the wind characteristics.

\section{Site, Instrumentation, and Methods}

2.1. Site and Instrumentation. All measurements relating to the results in this paper took place at Ny-Ålesund, Svalbard $\left(\mathrm{N} 78^{\circ} 55.287^{\prime}, \mathrm{E}^{\circ} 11^{\circ} 54.851^{\prime}\right)$, which is since 1968 a centre for different polar research institutions, also for the Alfred Wegener Institute AWI (AWIPEV research station). Ny-Ålesund is located in the roughly west-east orientated Kongsfjord on the west coast of Svalbard and, apart from the fjord entrance, surrounded by glaciers and mountains up to $800 \mathrm{~m}$ (see Figures 1(a) and 1(b)). Used are data of an eddy covariance system nearby $\mathrm{Ny}$-Ålesund (marked in Figure 1(b)) and corresponding model results of a so called hydrodynamic model approach $[14,15]$. All the eddy covariance data shown in this paper were sampled with $20 \mathrm{~Hz}$, the wind components and the sonic temperature were measured with a sonic anemometer (CSAT3, Campbell Scientific, Inc.) at a height of $2.1 \mathrm{~m}$ above ground. For the use of the hydrodynamic model approach the friction velocity, the temperature at measurement height, and the surface temperature are needed. The friction velocity in the following is always obtained via the sonic anemometer of the eddy covariance system. The air temperature in measurement height is obtained via platinum resistance measurement (Hygro-Thermogeber, Thies Clima; to avoid radiation errors installed in a ventilated protection hut) and the surface temperature via infrared temperature measurement (IR 100, Campbell Scientific). All values were collected at the same place.

The climatology of this measurement site is well described in, for example, [16], detailed background information to the behaviour of all important meteorological variables in the course of the year(s) can be found there.

2.2. Eddy Covariance. The eddy covariance method is nowadays a well known, detailed described, and popular method to determine the near surface turbulent vertical fluxes [10, 17-20]. The conditional equation is quite simple, however, a lot of assumptions have to be fulfilled for a meaningful use of the eddy covariance method. The most important assumptions are stationarity, horizontal homogeneity, and a vanishing mean vertical wind velocity regarding the time period, for which the turbulent flux should be determined. Making a scale analysis of the dominant forces near the earth surface leads to the determination equation for each vertical turbulent flux $Q_{x}$, here in kinematic units and in a general shape:

$$
Q_{x}=\overline{w^{\prime} x^{\prime}}
$$

$W$ stands for the vertical wind speed, $x$ stands for the quantity of interest, and the apostrophe indicates that the fluctuations of these quantities are needed. The right side of (1) equates to the covariance between the two components in this equation. To calculate the sensible heat flux in kinematic units, $x$ would be the temperature, for the latent heat flux the specific humidity and for the momentum flux the horizontal wind. In this way, each flux of interest can be calculated if the suitable measurement technique is available. To get the full turbulent spectrum the quantities of interest have to be measured in high resolution, $10-20 \mathrm{~Hz}$ is advisable.

The data postprocessing was made with the internationally compared eddy covariance software TK3 [21-23]. This software includes all state-of-the-art corrections, which have to be done to calculate the turbulent fluxes in a correct way, amongst others a coordinate rotation (double rotation was used here; see [19]) depending on the wind field on site $[24,25]$. Unless otherwise noted, the time average was $30 \mathrm{~min}$ for all calculations.

TK3 also includes a quality flag scheme (detailed described in [24]). This scheme combines a steady state test according to Foken and Wichura [26] and a test of the development of turbulent conditions using the integral turbulence characteristics, both are leading to a classification in 9 classes, which are then combined for an overall flag. At this point a few more words to integral turbulence characteristics (ITC's): integral turbulence characteristics are basic similarity characteristics of the atmospheric turbulence $[19,26]$ depending on the atmospheric stability. For the wind components $(u=$ along wind direction component, $v=$ across wind direction component, and $w=$ vertical wind component) they are calculated by dividing the standard deviation of the component of interest by the friction velocity

$$
\operatorname{ITC}_{u, v, w}=\frac{\sigma_{u, v, w}}{u_{*}},
$$

for scalar components the standard deviations are normalized by their dynamical parameters (e.g., the dynamical temperature $T_{*}$, if the temperature is investigated). The dynamical temperature is calculated as

$$
T_{*}=-\frac{\overline{w^{\prime} T^{\prime}}}{u_{*}} .
$$

ITC's depend on the atmospheric stability and are different constant values for different atmospheric stabilities. To test the development of turbulence, ITC's are compared to model functions determined by Foken et al. [27] for unstable conditions and to model functions determined by Thomas and Foken [28] for near neutral stratification. As there are no 


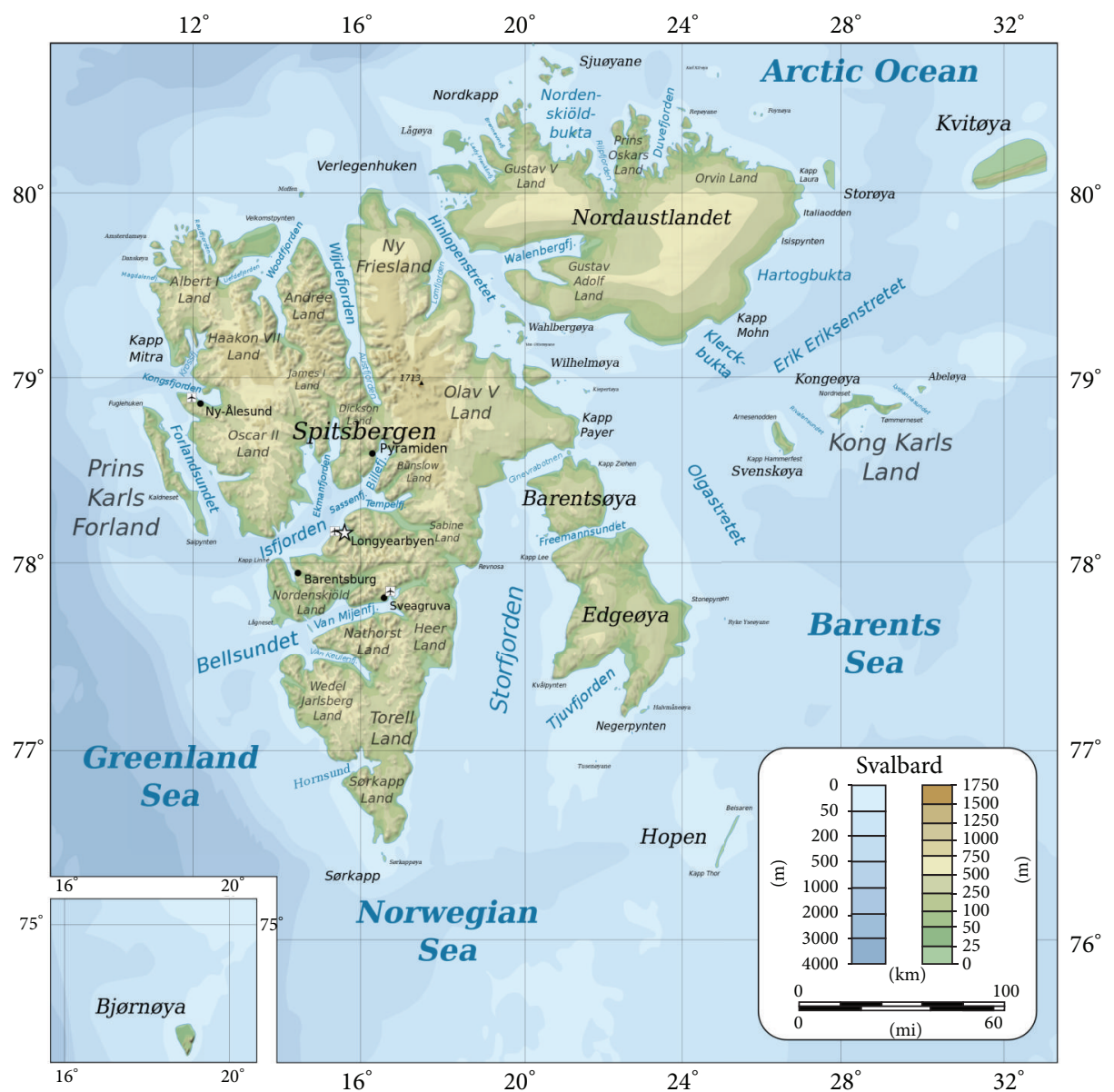

(a)

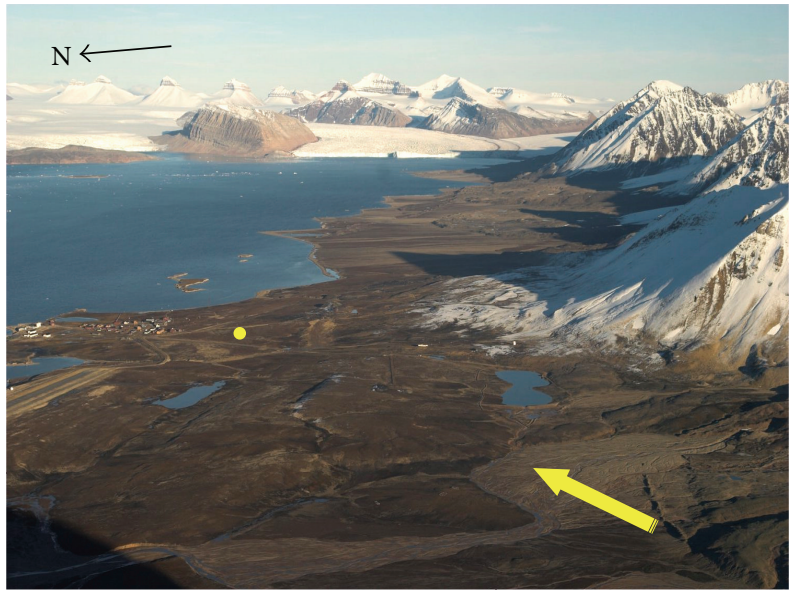

(b)

FIGURE 1: (a) Map of Svalbard (http://commons.wikimedia.org/wiki/File:Topographic_map_of_Svalbard.svg\#), (b) Kongsjord region with NyÅlesund [42]. Additionally marked are the eddy covariance site (yellow dot) and the main outflow direction of the Broggerbreen glacier (yellow arrow).

parameterisations for stable stratification available, the same parameterisation as in the unstable case is used for stable stratification. An ITC-test is not applied for the sensible heat flux under direct neutral conditions, because (3) is not well defined in this case.
The overall flag scheme combines then the steady-state test and the results of the ITC-test of the two time series, of which the covariance is calculated. If there is no agreement in the two ITC-tests, the higher flag is used for the overall classification (Table 1). 
TABLE 1: Overall flag system after Foken [43].

\begin{tabular}{lcc}
\hline Steady state flag & ITC flag & Final flag \\
\hline 1 & $1-2$ & $\mathbf{1}$ \\
2 & $1-2$ & $\mathbf{2}$ \\
$1-2$ & $3-4$ & $\mathbf{3}$ \\
$3-4$ & $1-2$ & $\mathbf{4}$ \\
$1-4$ & $3-5$ & $\mathbf{5}$ \\
5 & $\leq 5$ & $\mathbf{6}$ \\
$\leq 6$ & $\leq 6$ & $\mathbf{7}$ \\
$\leq 8$ & $\leq 8$ & $\mathbf{8}$ \\
9 & 9 & $\mathbf{9}$ \\
\hline
\end{tabular}

The authors of this scheme suggest using only data with flags 1-3 for fundamental research. Classes $4-6$ can be used for continuously running systems (e.g., in networks), 7 and 8 for orientation. Data of class 9 should be always excluded.

2.3. Hydrodynamic Model Approach (HMA). Another way to calculate the sensible heat flux, not often used but quite sophisticated, is a hydrodynamic three-layer model approach, developed originally for flux measurements above sea-water by Foken $[14,15]$, first applied above snow by Sodemann and Foken [29], and used for flux calculations in $\mathrm{Ny}$ Ålesund by Lüers and Bareiss [12] and Jocher [30]. This approach uses the temperature difference between surface and measurement height and a profile coefficient $\Gamma$, which is derived by separated integrating over the very small molecular boundary layer $(<1 \mathrm{~mm})$, the viscous buffer layer $(\approx 1 \mathrm{~cm})$, and the turbulent dynamic sublayer $(\approx 1-2 \mathrm{~m})$ using parameterized dimensionless thickness and normalized temperature differences. For heights exceeding the turbulent dynamic sublayer, stability influence according to the MoninObukhov-similarity has to be considered. So called universal functions (e.g., [31-33]) are then enclosed to the determination equation depending on the dimensionless stability parameter $z / L$ with the measurement height $z$ and the Obukhov-length $L$, which describes the ratio between shear forces, thermal forces, and buoyancy forces [34, 35]. In the case of unstable stratification $z / L$ is negative, in the case of stable stratification positive (damped turbulence). Values of $z / L$ fluctuating around zero mean neutral stratification. This stability influence can be neglected for measurement heights in or below the turbulent dynamic sublayer. For the results in this paper we assumed to be in or below the turbulent dynamic sublayer, which is most probably justified in the summer period due to quite well developed turbulence, but also in winter times due to a certain snow layer which reduces the effective measurement height. Tests including stability influence in the hydrodynamic model approach for selected periods agreed well with this statement, there were no significant differences between the shown results with or without included stability influence in the hydrodynamic model approach for all seasons in the course of the year.
The final formula for the profile coefficient $\Gamma$ is according to Foken [15]:

$$
\Gamma=\frac{\kappa \cdot u_{*}}{\left(\left(\delta_{T} \cdot u_{*}\right) / \nu\right) \cdot \kappa \cdot \operatorname{Pr}+4 \cdot \kappa+\ln \left(\left(u_{*} \cdot z\right) /(30 \cdot \nu)\right)}
$$

$\kappa=0.4$ [33] means here the von-Karman constant, $u_{*}$ the friction velocity. $\delta_{T}$ represents the thickness of the molecular temperature boundary layer, $\operatorname{Pr}=0.71$ the molecular-turbulent Prandtl number, $z$ the measurement height, and $v$ the temperature dependent kinematic viscosity of air $\left(\mathrm{m}^{2} \mathrm{~s}^{-1}\right)$ for which a value of $1.3 * 10^{-5}$ was used for all calculations (this is the value for an air temperature of $0^{\circ} \mathrm{C}$ and an air pressure of $1013 \mathrm{hPa}$ ). The original literature names a value of 20 in the denominator of the logarithmic term in (4), this value was adapted in the course of the last years and now it is recommended to use a value of 30 (personal communication original author HMA).

The friction velocity $u_{*}$ in (4) is directly obtained by the sonic anemometer using (1) and the following correlation between friction velocity and the kinematic momentum flux $\overline{u^{\prime} w^{\prime}}$ :

$$
u_{*}=\sqrt{-\overline{u^{\prime} w^{\prime}}}
$$

For (5) only the vertical wind and the horizontal wind component $\mathrm{u}$ are needed, the influence of the horizontal wind component $v$ can be neglected due to the coordinate rotation of the sonic anemometer data in the mean wind.

The integral between the surface and the top of the molecular boundary layer depends on friction velocity, the kinematic viscosity of air, and the thickness of the molecular temperature boundary layer. For this hydrodynamic model approach a fundamental change of the behaviour of the molecular boundary layer at a friction velocity of $0.23 \mathrm{~m} \mathrm{~s}^{-1}$ was found $[14,36]$, so the following distinction of cases is made for the corresponding term in $\Gamma$ (the line in the brackets of the right side of (6) is just a separation line, no quotient):

$$
\frac{\delta_{T} \cdot u_{*}}{v}=\left\{\frac{6, u_{*} \leq 0.23 \mathrm{~m} \mathrm{~s}^{-1}}{12, u_{*}>0.23 \mathrm{~m} \mathrm{~s}^{-1}}\right\} \text {. }
$$

Though this distinction of cases is very strictly speaking just valid over water surfaces, we adopted it following the literature to this topic (see [12]). This distinction is state-ofthe-art also over land.

For the sensible heat flux $Q_{H}$ follows then in kinematic units $\left(\mathrm{K} \mathrm{m} \mathrm{s}^{-1}\right)$ :

$$
Q_{H}=\Gamma \cdot\left(T_{s}-T_{z}\right)
$$

$T_{s}$ stands in this equation for the surface temperature and $T_{z}$ for the air temperature in measurement height.

If the sensible heat flux and the air temperature in a given height are known, formula (7) can be rewritten to derive the surface temperature as following:

$$
T_{s}=\frac{Q_{H}}{\Gamma}+T_{z}
$$




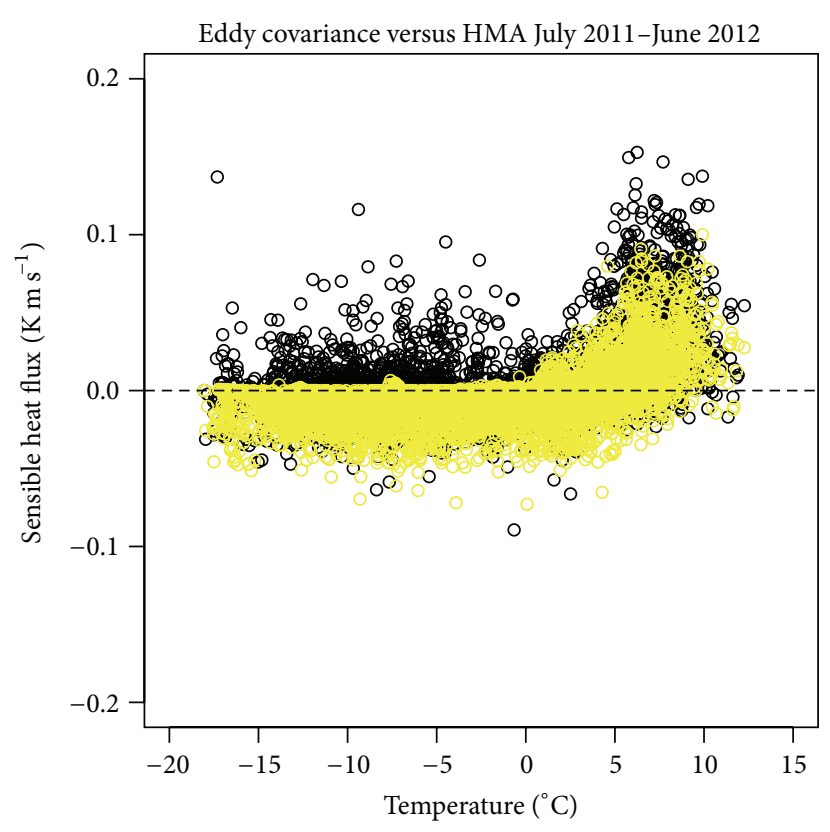

(a)

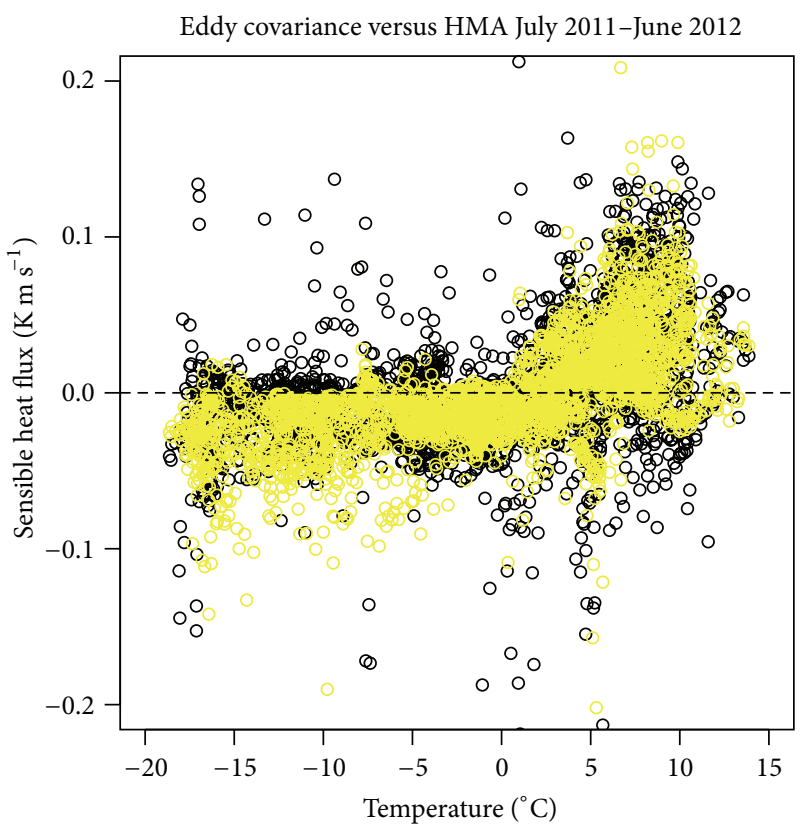

(b)

FIGURE 2: 30 min averages of the kinematic sensible heat flux $\left(\mathrm{K} \mathrm{m} \mathrm{s}^{-1}\right)$ for the period July 2011 to June 2012, plotted against the air temperature in measurement height (eddy covariance: black dots, HMA: yellow dots): (a) sensible heat fluxes for friction velocities $\leq 0.23 \mathrm{~m} \mathrm{~s}{ }^{-1}$, (b) sensible heat fluxes for friction velocities $>0.23 \mathrm{~m} \mathrm{~s}^{-1}$.

Unless otherwise stated, the mentioned temperature values were averaged in $30 \mathrm{~min}$ intervals to combine them with the friction velocity values obtained by the flux calculations with TK3.

\section{Results}

To get started with the results, Figures 2(a) and 2(b) show an overview of the $30 \mathrm{~min}$ averages of the kinematic sensible heat flux for the period July 2011 to June 2012, plotted against the air temperature in measurement height and according to (6) divided for friction velocities $\leq 0.23 \mathrm{~m} \mathrm{~s}^{-1}$ (Figure 2(a)) and higher friction velocities (Figure 2(b)). Several topics are obvious at first view on these plots: both figures show that the results of the HMA are limited in the negative temperature range in the way that positive sensible heat fluxes in the negative temperature range are not or only partially possible. This is a general problem of model approaches, which use the temperature gradient between a certain height and the surface to calculate the sensible heat flux, the results are "too stable," if the surface temperature is lower than the temperature in measurement height (e.g., [5]). This means: outside the short summer period with surface temperatures higher than the temperatures in measurement/model height, positive sensible heat fluxes cannot be reproduced by these model approaches. And furthermore, negative sensible heat flux results of these model approaches outside the summer period are often too large in comparison to, for example, eddy covariance results.

On the other hand the eddy covariance results in both figures reproduce positive sensible heat fluxes in negative temperature ranges, but care should be taken here for the interpretation: Jocher et al. [11] showed that external gravity waves outside the summer period lead to fictitious positive sensible heat fluxes with the eddy covariance method, especially for low friction velocities. Foken and Wichura [26] described this methodical problem in detail, clearly to see is this fact especially in the pronounced "hill" of the eddy covariance results in the negative temperature range for low friction velocities in Figure 2(a), the next sections will pick up this topic again. Furthermore, in Figure 2(a) it is well to see that the HMA cannot fully reproduce the positive eddy covariance fluxes in the positive temperature range for low friction velocities. Generally the accordance is better for high friction velocities (Figure 2(b)), but there is still a deviation.

3.1. Seasonal Characteristics of the Sensible Heat Flux. Two major flux regimes are obvious in the course of the year. On the one hand the short summer period in which convection is possible (called "convective" in the following), on the other hand the rest of the year with mostly stable or neutral conditions. The transition between the two periods is quite fast; when the snow melt is over and the surface has dried, the flux regime can rapidly change to convective conditions from one hour to the next. Values of two summers are combined here. By investigating the general behaviour of the sensible heat flux we proved in detail if this is justified and came to the conclusion that there is no reason against combining the periods 1.7.2011-31.8.2011 and 16.6.2012-30.6.2012 to one "convective" period. Outside this period the incoming shortwave radiation is too weak to generate convection (or the surface is still covered with snow or melting water which inhibits 
a clear warming of the surface), the incoming shortwave radiation is the main driving parameter for the flux regime in summer. Figures 3(a) and 3(b) show the sensible heat flux calculated by the eddy covariance method for the mentioned summer period, plotted against the corresponding results of the hydrodynamic model approach. In Figure 3(a) the results for friction velocities $\leq 0.23 \mathrm{~m} \mathrm{~s}^{-1}$ are shown, in Figure 3(b) for friction velocities $>0.23 \mathrm{~m} \mathrm{~s}^{-1}$. As pointed out in the section before, for low friction velocities the results of the hydrodynamic model approach are systematically lower than the results of the eddy covariance method (Figure 3(a)). This difference is also visible at the fluxes for friction velocities $>0.23 \mathrm{~m} \mathrm{~s}^{-1}$ but a little bit less pronounced. We will come back later to this issue and discuss if it is necessary to adapt the parameterisation of the hydrodynamic model approach in summer over land. The same values as in Figures 3(a) and 3(b) but only for the eddy covariance derived quality flags 1-3 are plotted in Figures 3(c) and 3(d). There are no big differences obvious in the general behaviour of the fluxes comparing Figures 3(a) and 3(b) against Figures 3(c) and 3(d).

The rest of the year behaves completely different to the short summer period; in Figures 3(e) and 3(f) the sensible heat fluxes for this period are shown, again separated in two classes with the values for friction velocities $\leq 0.23 \mathrm{~m} \mathrm{~s}^{-1}$, (Figure 3(e)) and for friction velocities $>0.23 \mathrm{~m} \mathrm{~s}^{-1}$ (Figure $3(\mathrm{f})$ ). Figure 3(e) shows on the one hand clearly that the hydrodynamic model approach does hardly generate positive fluxes outside the summer period and on the other hand the problem with the external gravity waves, generating fictitious positive sensible heat fluxes using the eddy covariance method. Outside the summer period the longwave radiation balance is the main driving parameter of the flux regime, which can lead to strong near-surface cooling and thereby katabatic outflows of the glaciers in the Kongsfjord facilitating the formation of near-surface external gravity waves. For friction velocities $>0.23 \mathrm{~m} \mathrm{~s}^{-1}$ the spreading of the results is larger and the problem with the external gravity waves is mostly gone due to a better mixing of the air produced by the friction (Figure 3(f)). But if we look on the same values, now only plotted for quality flags $1-3$, it is evident that only a small range of eddy covariance values fluctuating around zero is left (Figures $3(\mathrm{~g})$ and $3(\mathrm{~h})$ ). We will discuss the flagging system of TK3 for stable conditions in Section 3.3.3 and check if this huge elimination of data is justified or if there are adaptations necessary in the flagging system of TK3.

\subsection{Sensible Heat Flux Characteristics Depending on Wind} Direction. This section shall highlight the connection between the near-surface turbulent flux behaviour and the wind direction at the measurement site. Figure 4 shows a wind rose (different wind classes are represented by different colours (see legend, values in $\mathrm{m} \mathrm{s}^{-1}$ ), the dashed circles represent the relative frequency) for the investigation period July 2011 to June 2012, built with data of the sonic anemometer at the eddy covariance site. Three main wind sectors are obvious: first easterly directions following the Kongsford orientation (canalisation effect), second a peak at about 220-230 degree which is predominantly correlated with katabatic outflows of the Broggerbreen glacier (the main outflow direction of this glacier is marked in Figure 1(b)), and third westerly directions in the case of wind blowing into the fjord entrance. The main features of Figure 4 are in agreement with corresponding investigations of the Kongsfiord wind field (e.g., [16, 37]). For the following discussion a data separation in 3 wind sectors is made (compare also Figure 1(b)): sector 1 is in the following named as "normal" sector $\left(20^{\circ}-150^{\circ}\right.$, wind comes in $44.7 \%$ of all data from this sector), sector 2 as "disturbed" sector (directly influenced by the Zeppelin mountain and Broggerbreen glacier south and south-west of Ny-Ålesund, $150^{\circ}-270^{\circ}, 35.9 \%$ of all data), and sector 3 as "synchronisation" sector $\left(270^{\circ}-20^{\circ}, 19.4 \%\right.$ of all data). "Synchronisation" means, in this context, that we can assume the same conditions in the whole Kongsfjord, because the wind is blowing directly into the ford entrance and synchronises herewith the flux behaviour in the whole fjord, which was detected by Jocher et al. [11]. The meteorological conditions which give rise to such "synchronisation events" are discussed at the end of this section.

Continuing the earlier introduced data separation in two friction velocity classes, Figure 5(a) shows the kinematic sensible heat fluxes (eddy versus HMA) for the time window 16.6.-31.8. and friction velocities $\leq 0.23 \mathrm{~m} \mathrm{~s}^{-1}$, in terms of colour (see legend) splitted in the 3 mentioned wind sectors. The general behaviour of the sensible heat flux is similar for all wind direction sectors, but the range of the values corresponding to wind directions from the "disturbed" sector is clearly smaller than for the two other wind sectors. An explanation for that could be that the surface warming is damped for this wind sector by colder air flowing down the Broggerbreen glacier also in summer time during calm wind conditions (compare also Figure 1(b)). The sensible heat flux behaviour is changing if the wind speed rises. Figure 5(b) shows the kinematic sensible heat fluxes (Eddy versus HMA) for the same period as in Figure 5(a) but for friction velocities $>0.23 \mathrm{~m} \mathrm{~s}^{-1}$. In the range of positive flux values the sectors "normal" and "synchronisation" agree furthermore quite well, but for the "normal" wind sector now also negative flux values are generated, which are not apparent if the wind is blowing from the sector $270^{\circ}-20^{\circ}$. These negative flux values might be caused by evaporation and an enhanced oasis effect, which means that the latent heat flux "steals" energy from the sensible heat flux to keep evaporation alive. The "synchronisation" sector is more maritime and brings often clouds from the open ocean, evaporation is damped. On the other hand evaporation is fostered in the "normal" sector under clear conditions and high wind speeds. In the "disturbed" sector in turn the wind speed is limited by the mountains (compare Figures 1(b) and 4). This sector also shows a quite different flux behaviour for positive flux values. The correlation between eddy covariance values and HMA values which is in the positive flux range quite similar for the sectors "normal" and "synchronisation" differs now clearly. A possible explanation could again be the down-flow of colder air from the glacier and still existing snow fields in this sector, as described for the flux values for the same period and small friction velocities. The higher wind speeds foster now 


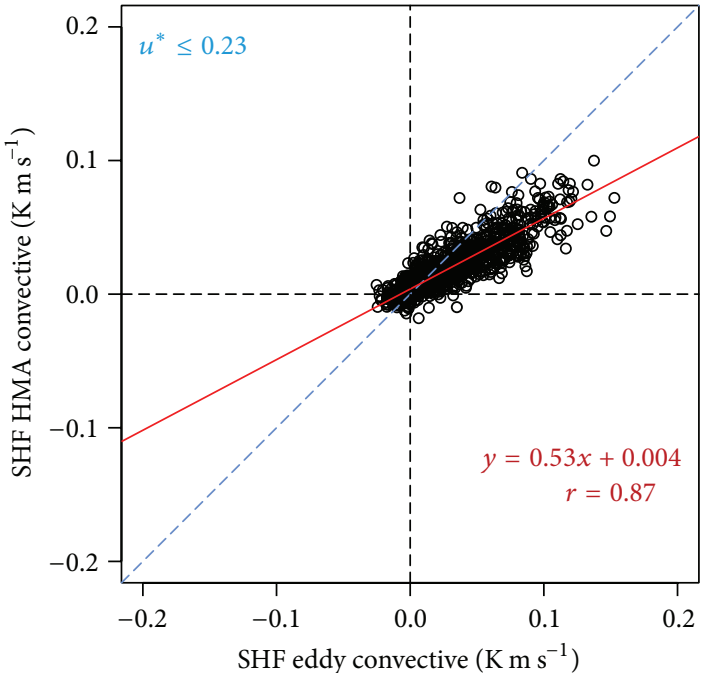

(a)

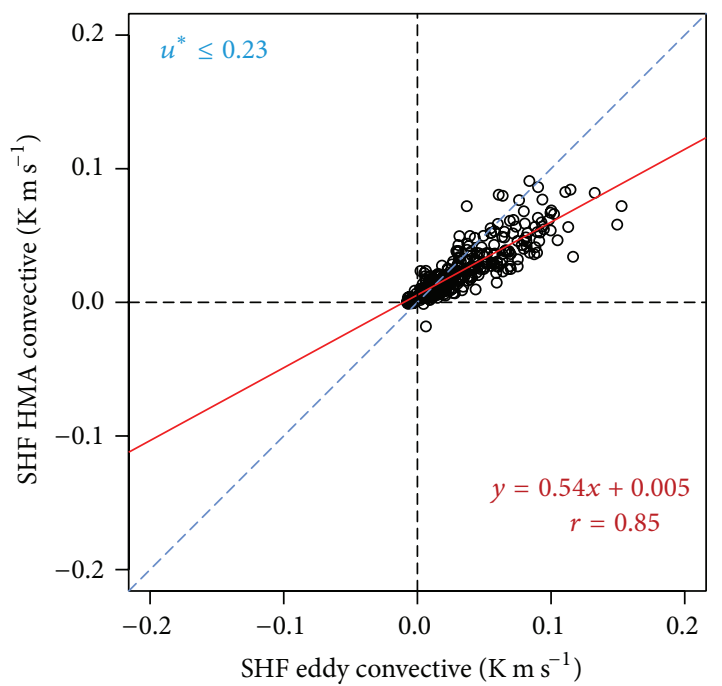

(c)

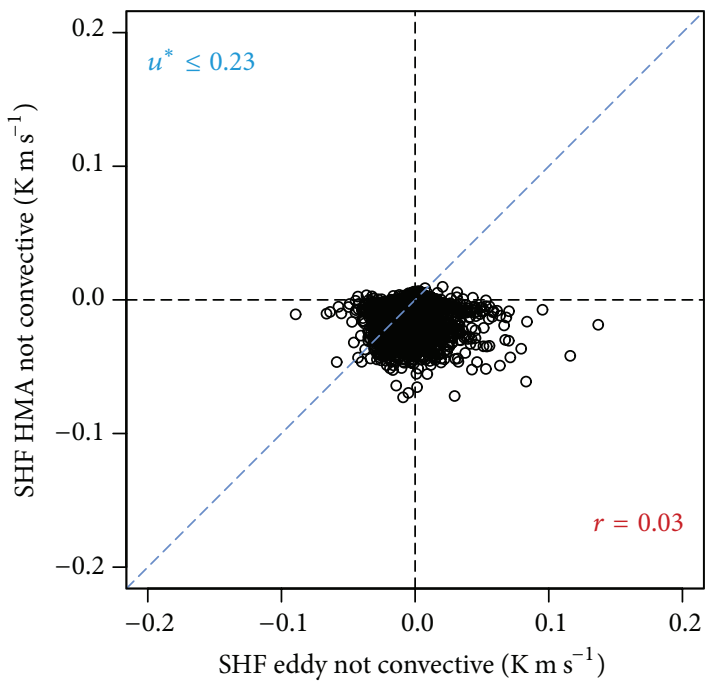

(e)

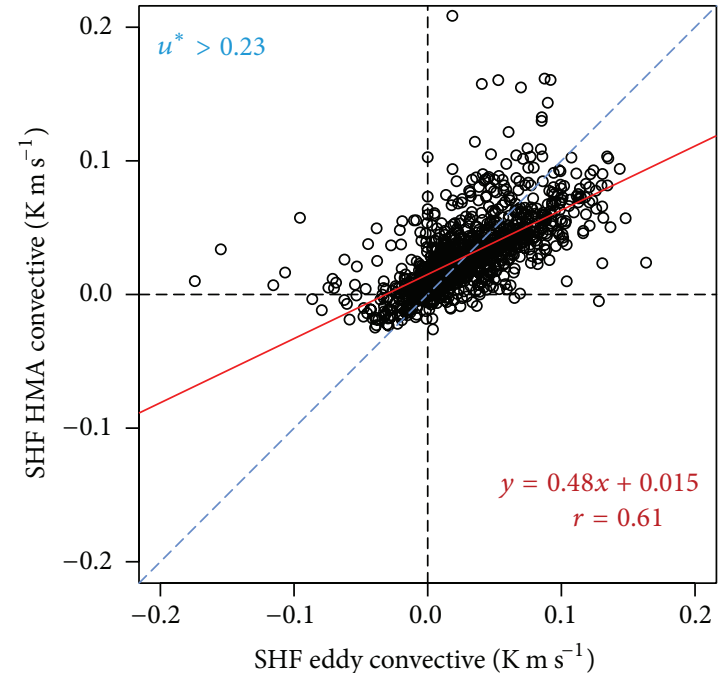

(b)

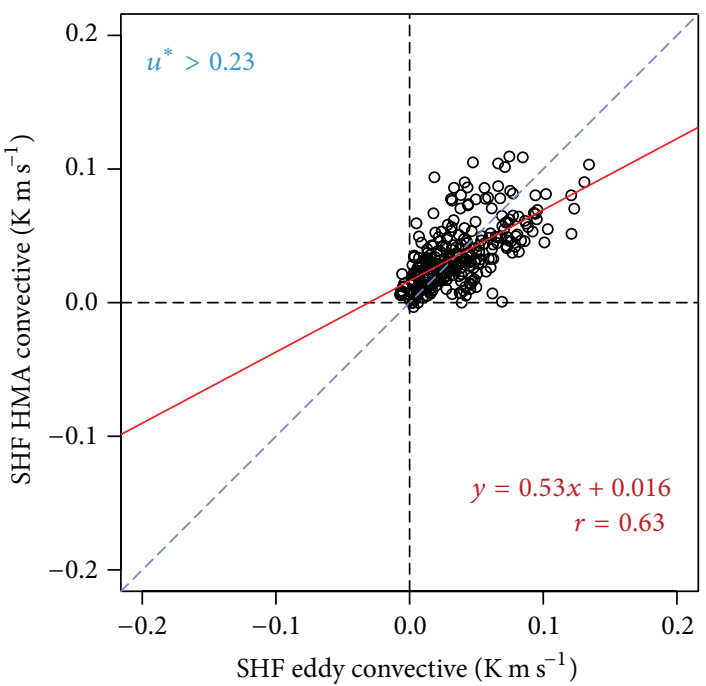

(d)

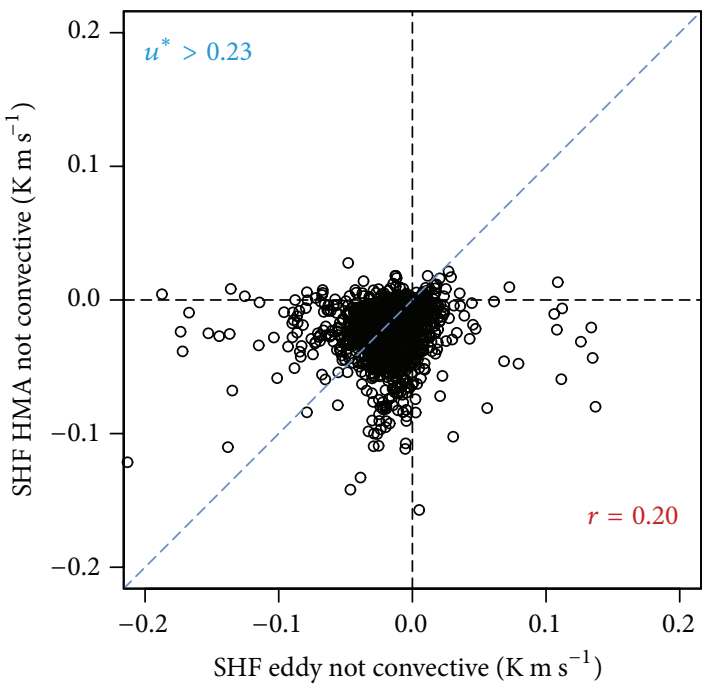

(f)

Figure 3: Continued. 


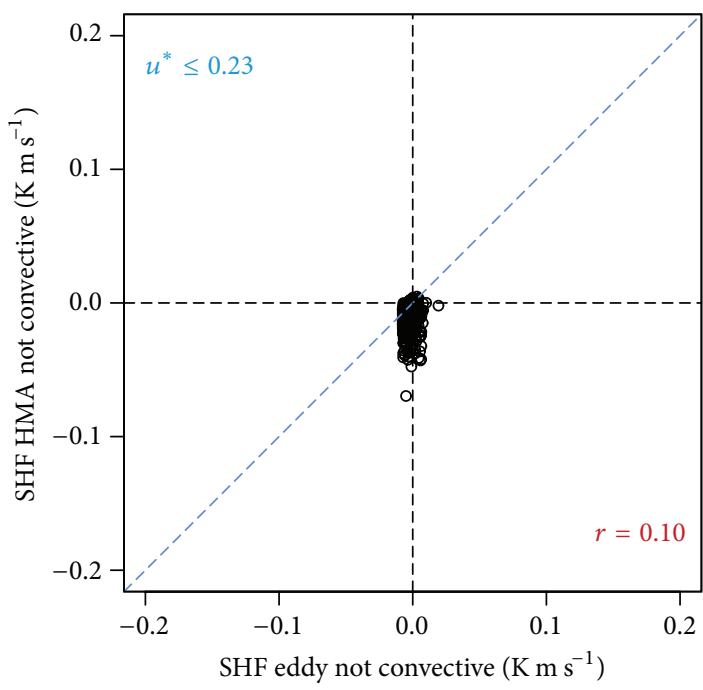

(g)

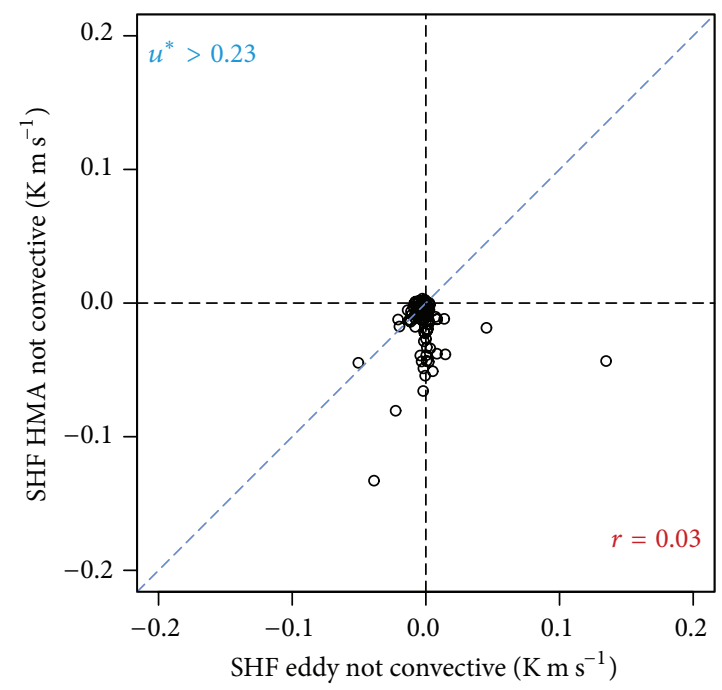

(h)

FIGURE 3: $30 \mathrm{~min}$ averages of the kinematic sensible heat flux $\left(\mathrm{K} \mathrm{m} \mathrm{s}^{-1}\right)$, eddy covariance versus HMA. Additionally shown is the correlation coefficient between the two data series and the linear regression (line and equation) for data from the convective period: (a) for the time window 16.6. to 31.8. and friction velocities $\leq 0.23 \mathrm{~m} \mathrm{~s}^{-1}$, (b) for the time window 16.6. to 31.8. and friction velocities $>0.23 \mathrm{~m} \mathrm{~s}^{-1}$, (c) Figure 3 (a) for quality flags 1-3, (d) Figure 3(b) for quality flags 1-3, (e) for the time window 1.9. to 15.6. and friction velocities $\leq 0.23 \mathrm{~m} \mathrm{~s}^{-1}$, (f) for the time window 1.9. to 15.6. and friction velocities $>0.23 \mathrm{~m} \mathrm{~s}^{-1}$, (g) Figure 3(e) for quality flags 1-3, and (h) Figure 3(f) for quality flags 1-3.

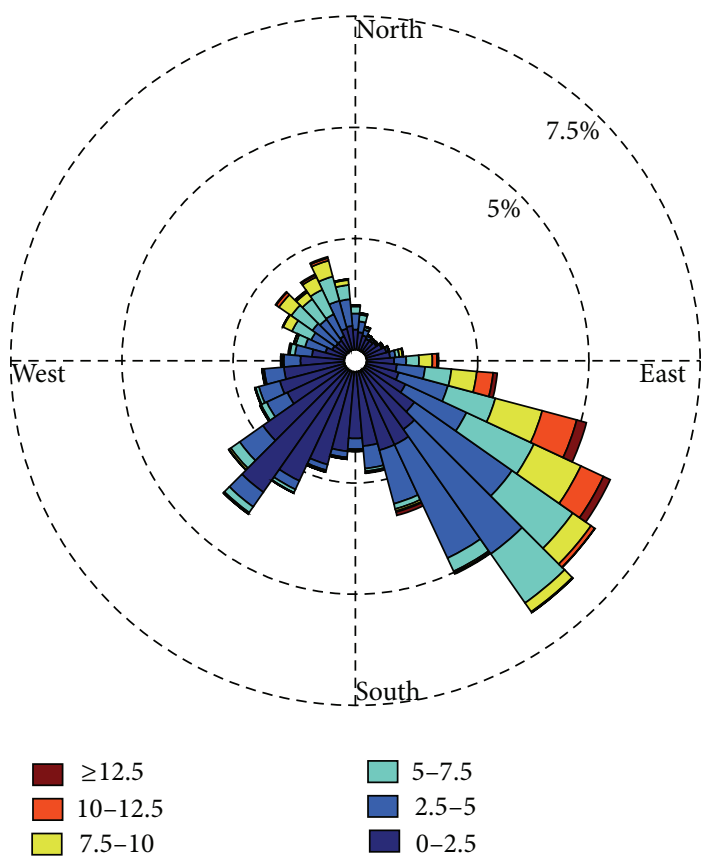

FIGURE 4: Wind rose for the investigation period July 2011 to June 2012, built with data of the sonic anemometer at the eddy covariance site (compare Figure 1(b)). Different wind classes are represented by different colours (see legend, values in $\mathrm{m} \mathrm{s}^{-1}$ ); the dashed circles represent the relative frequency.

the advection of colder air down the glacier and mountains, otherwise the shortwave radiative heating of the surface at the measurement site is still the same. This leads to higher temperature differences between surface and measurement height at higher wind speeds and herewith higher flux values using HMA in comparison to the flux behaviour for the sectors "normal" and "synchronisation."

Figure 5(c) shows the kinematic sensible heat fluxes (eddy versus HMA) for the time window 1.9.-15.6. and friction velocities $\leq 0.23 \mathrm{~m} \mathrm{~s}^{-1}$. Well to see is the already mentioned limitation of the model approach in the range of positive flux values. Model approaches are in general rarely able to reproduce positive turbulent fluxes (which can also occur in stable conditions) because of their usage of the temperature gradient between measurement height and surface for the flux calculation. This gradient is almost always positive outside the summer period in Arctic tundra regions due to longwave radiative loss at the interface surface-air and the weak or missing shortwave radiative input in this time period. The most prominent phenomenon in Figure 5(c) is the huge amount of clearly positive flux values in the "disturbed" sector, generated by the eddy covariance method. Responsible for that are the earlier introduced external gravity waves which are triggered by near-surface katabatic outflows (often with only 1-2 m depth) of the Broggerbreen glacier (compare Figure 1(b)) which occur in quite calm and clear conditions (wind speed $<5 \mathrm{~m} \mathrm{~s}^{-1}$, no clouds; compare [11]). Considering the eddy covariance results we see furthermore that the values in the "synchronisation" sector are more or less oscillating around zero, while in the "normal" sector clearly more negative flux values can occur. This is to explain with the more maritime character in the "synchronisation" sector (the wind is blowing directly from the open water of the ocean and the fjord to the eddy covariance measurement site) in contrast to the "normal" sector, which follows a 


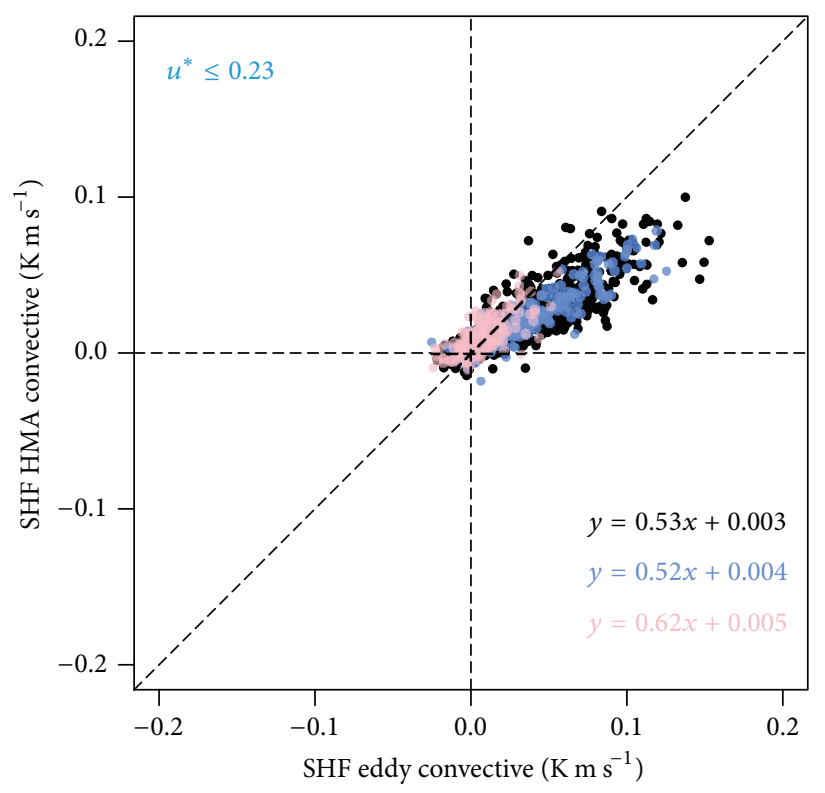

(a)

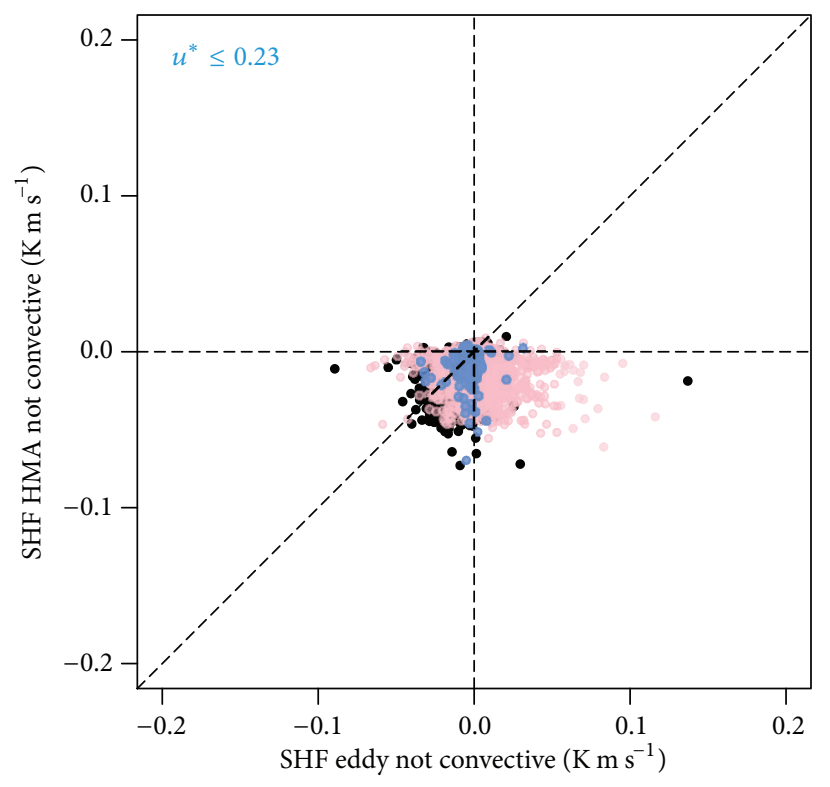

(c)

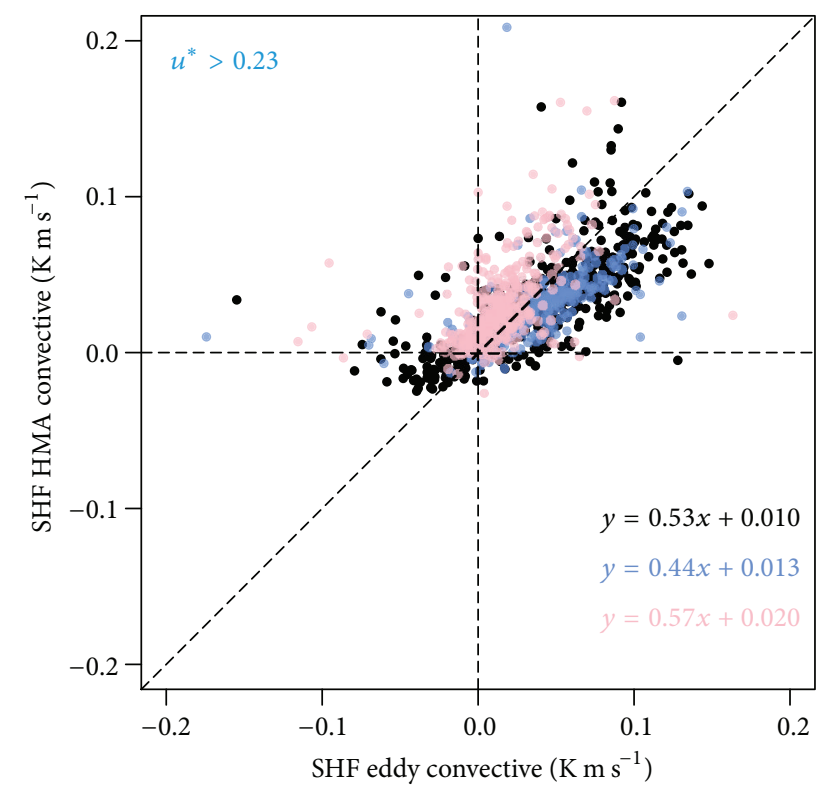

(b)

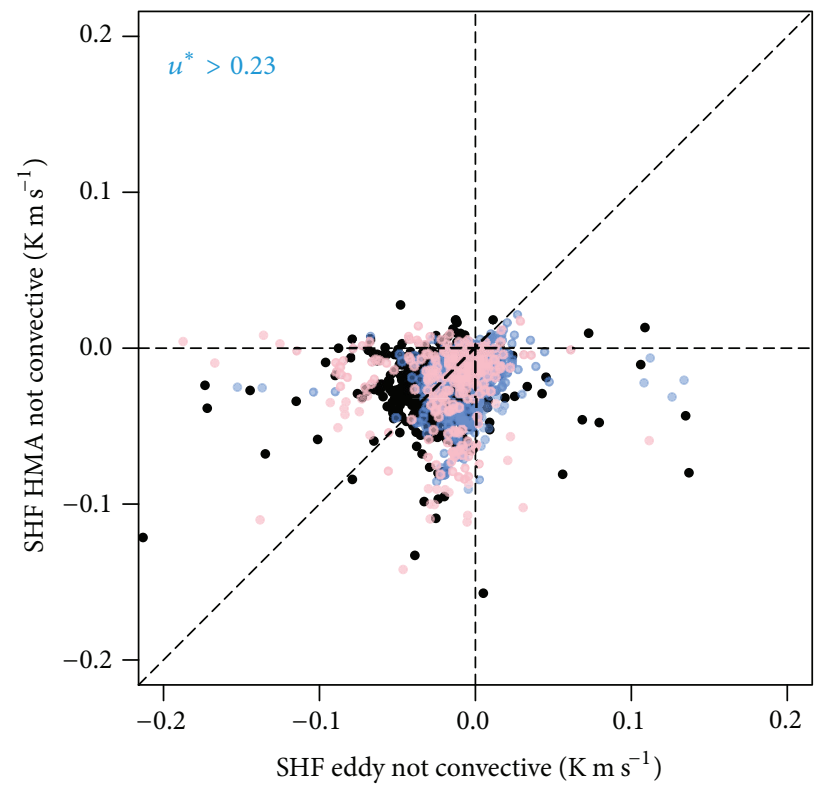

(d)

FIGURE 5: Kinematic sensible heat flux eddy covariance versus sensible heat flux HMA (30 min averages, $\mathrm{K} \mathrm{m} \mathrm{s}^{-1}$ ), separated for the three wind sectors "normal" $\left(20^{\circ}-150^{\circ}\right.$, marked with black dots), "disturbed" $\left(150^{\circ}-270^{\circ}\right.$, marked with pink dots), and "synchronisation" $\left(270^{\circ}-20^{\circ}\right.$, marked with blue dots). Additionally shown are the linear regression equations for the different sectors (colour-coded) for data from the convective period: (a) for the time window 16.6. to 31.8. and friction velocities $\leq 0.23 \mathrm{~m} \mathrm{~s}^{-1}$, (b) for the time window 16.6. to 31.8 . and friction velocities $>0.23 \mathrm{~m} \mathrm{~s}^{-1}$, (c) for the time window 1.9. to 15.6. and friction velocities $\leq 0.23 \mathrm{~m} \mathrm{~s}^{-1}$, and (d) for the time window 1.9. to 15.6. and friction velocities $>0.23 \mathrm{~m} \mathrm{~s}^{-1}$.

more continental behaviour (wind is blowing mostly from directions with a land or snow surface). Figure 5(d) shows the same values as Figure 5(c) but now for friction velocities $>0.23 \mathrm{~m} \mathrm{~s}^{-1}$. Obvious on a first view is the more fluctuating flux behaviour due to the higher wind speeds. The huge amount of fictitious positive flux values in the "disturbed" wind sector generated by the eddy covariance method in the case of external gravity waves is now gone due to the enhanced air mixing at higher friction velocities, which avoids the arrival of katabatic cold air outflows from the Broggerbreen glacier at the eddy covariance measurement site. Figure 5(d) confirms the above established theory that the "normal" wind sector is more continental influenced and the "synchronisation" sector more maritime: the "normal" sector generates much more negative flux values than the "synchronisation" sector. 
Back to the topic "synchronisation": the investigations in the course of this paper led to the knowledge that we can find a direct connection between the synoptic situation and the cases of wind blowing from the "synchronisation" sector into the Kongsfjord, and herewith a direct connection between the synoptic situation and the flux behaviour in these cases. For the other introduced wind sectors this connection is much more complicated due to the surrounding orography, channeling effects, and the influence of glacier outflows, so we start at this point with the description of the major synopticscale/small-scale connection for the "synchronisation" sector: in most of the cases of synchronisation a correlation with a low pressure system in the north-east of Svalbard occurs. This is the predominant synoptic situation for a westerly flow in the roughly west-east orientated Kongsfjord and herewith a synchronisation of the near-surface processes in the fjord. To investigate the topic "synchronisation" we proceeded at this point as following: as synchronisation event we classified a timev period of at least 4 hours wind blowing from the sector $300^{\circ}-360^{\circ}$ (to be sure to investigate a "real" synchronisation event the sector was chosen a bit narrower than at the definition for the 3 wind direction classes earlier in this paper). Filtering the sonic anemometer data (1 min averages) at the eddy covariance measurement site by these criteria for the whole year data which is presented in this paper (July 2011 to June 2012) and looking at the large scale synoptic situation for the in this way obtained synchronisation periods led to following statistical distribution: the 73 events which were found for the whole year correlate in 55 cases with the already above mentioned low pressure system in the north-east of Svalbard, the remaining 18 cases cannot be brought in a connection with a specific synoptic situation. Furthermore the 55 cases with a low pressure system in the north-east of Svalbard can be roughly divided in cases where the rotation of the low pressure system causes the wind field in the Kongsfjord (46 cases) and in cases where most probably a geostrophic flow causes the wind field in Kongsfjord ( 9 cases; the low pressure system in the northeast of Svalbard and a corresponding high pressure system in the south-west of Svalbard are quite far away from each other). For statements to the synoptic situation we used in all cases 6 hour averaged ERA-Interim Reanalysis data, which are provided by the ECMWF (European centre for medium-range weather forecasts). Investigated were the surface pressure $(\mathrm{hPa})$, the wind speed $\left(\mathrm{m} \mathrm{s}^{-1}\right)$ in $850 \mathrm{hPa}$, the wind vector in $850 \mathrm{hPa}$, and the geopotential height in $850 \mathrm{hPa}$. $850 \mathrm{hPa}$ was chosen to have the "pure" synoptic circumstances without influence of the earth's surface. To make the statements visible, Figure 6 shows an example plot of the mentioned ERA-Interim Reanalysis data for 28.5.2012, 12 UTC, Svalbard is marked there with a white cross. This date was chosen due to its excellent representativeness for the described "synchronisation" phenomenon. In Figure 6 the wind speed in $850 \mathrm{hPa}$ (colours), the wind vector in $850 \mathrm{hPa}$ (arrows) and the geopotential height in $850 \mathrm{hPa}$ (lines) are shown. Well to see is the strongly developed low pressure system with its centre north-east of Svalbard (grey contour lines). The pronounced pressure gradient between
Svalbard and Greenland leads to intense northerly to northwesterly flow (vectors) with wind speeds around $20 \mathrm{~m} \mathrm{~s}^{-1}$ (shading colours). Figure 6 makes clearly visible that this type of pressure distribution leads to strong wind blowing into the fjord entrance of the Kongsfjorden and therefore a synchronisation of the wind field in the whole fjord.

The investigations concerning the correlation between surface processes and the synoptic situation are still ongoing, also for the other wind sectors which seem to behave much more complicated.

3.3. Additional Remarks. In this section we will discuss three important issues which became obvious in the course of this paper a bit more in detail. Adaptations of (6) are presented in Section 3.3.1, both for low and high friction velocities to improve the performance of the hydrodynamic model approach during summer over land (see also figures 3(a) and 3(b)).

Directly following out of these statements is Section 3.3.2: further application possibilities of the HMA.

In Section 3.3.3 we will discuss the flagging system of TK3 for the sensible heat flux during stable conditions and investigate the integral turbulence characteristics to possibly improve the current used parameterisations of the integral turbulence characteristics in TK3 during stable conditions (see also Figures $3(\mathrm{~g})$ and $3(\mathrm{~h})$ ).

3.3.1. HMA during Summer over Land. Thinking back to Section 3.1 we recall a systematic deviation between the sensible heat fluxes obtained by the eddy covariance method and by the HMA during summer (compare Figures 3(a) and 3(b)), the HMA-fluxes are continuously lower. Foken et al. $[14,36,38]$ provide the theory for using a value of 6 for (6) in the case of friction velocities $\leq 0.23 \mathrm{~m} \mathrm{~s}^{-1}$ and a value of 12 in the case of friction velocities $>0.23 \mathrm{~m} \mathrm{~s}^{-1}$. This equation describes the behaviour of the molecular temperature boundary layer above a water surface in the profile coefficient (4) using HMA.

Over land obviously an adaptation is necessary: we set in a kind of case study the values for (6) to 1 (former 6) for friction velocities $\leq 0.23 \mathrm{~m} \mathrm{~s}^{-1}$ and to 2 (former 12) in the case of friction velocities $>0.23 \mathrm{~m} \mathrm{~s}^{-1}$. Figure 7 (a) shows the in this way recalculated kinematic sensible heat flux values for low friction velocities, Figure 7(b) for friction velocities $>0.23 \mathrm{~m} \mathrm{~s}^{-1}$. Well to see is that the general behaviour of the HMA values fits now better to the general behaviour of the eddy covariance values (even if the correlation coefficient is not changing significantly in comparison to Figures 3(a) and 3(b), but this coefficient is just an information about the linear relationship of two timelines). This means in words: the molecular temperature boundary layer over land during the convective period is less developed than it would be over a water surface. This can be lead back to the higher roughness of the land surface comparing to a water surface.

Because there is still a deviation in Figures 7(a) and 7(b) comparing eddy covariance results and HMA during the convective period an additional point shall be mentioned here: Westermann et al. [39] investigated the spatial 


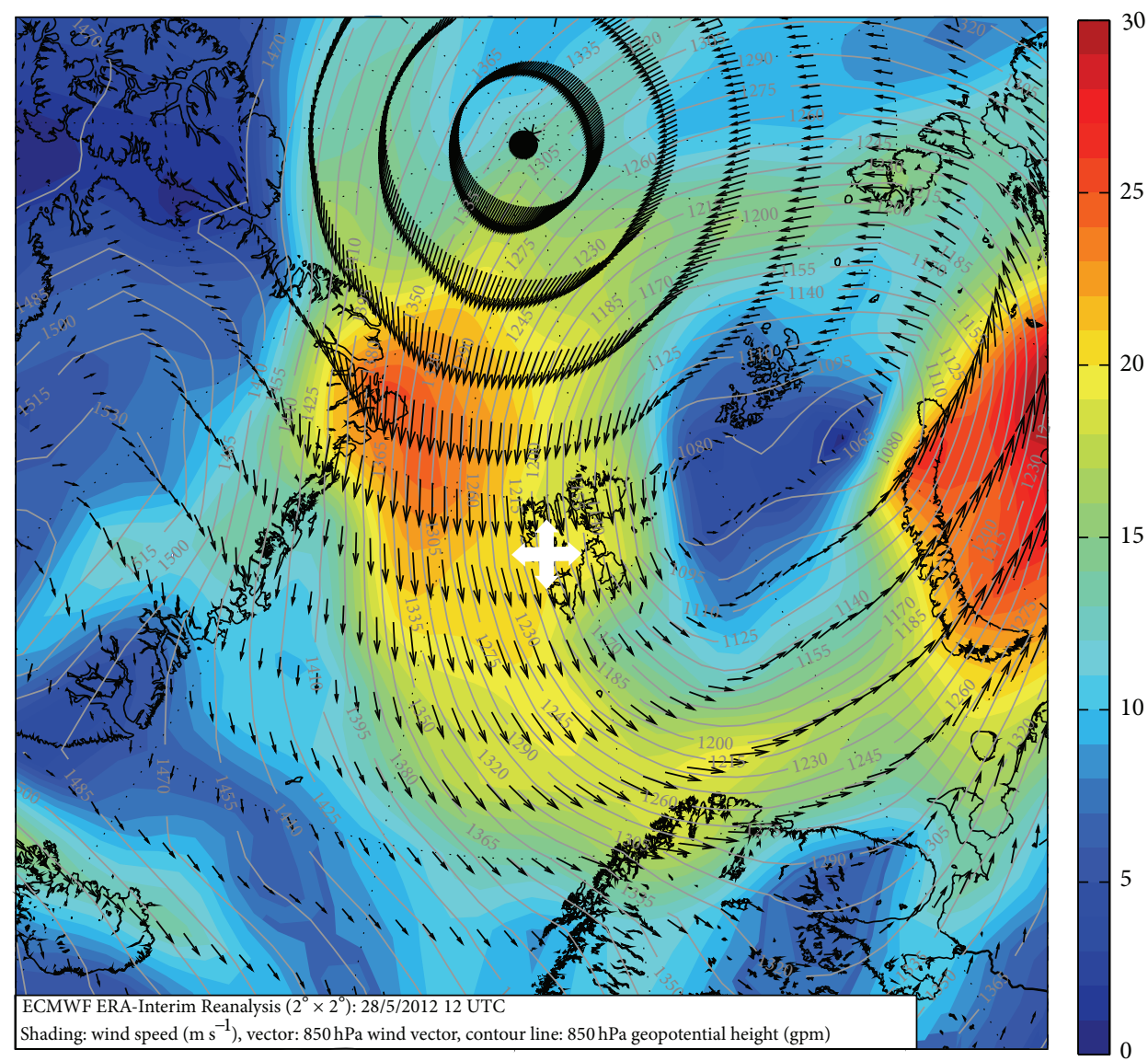

FIGURE 6: ERA-interim reanalysis data for 28.5.2012, 12 UTC. The wind velocity in $850 \mathrm{hPa}$ is shown in different colours, the wind vector in $850 \mathrm{hPa}$ with arrows, and the geopotential height in $850 \mathrm{hPa}$ with lines. Additionally, Svalbard is marked with a white cross.

and temporal variations of summer surface temperatures at another measurement site near Ny-Ålesund, this site is in the direct vicinity of a small river. They detected that quite big differences in surface temperatures on small spatial scales are possible mainly depending on the surface moisture. For the measurement site which is presented in this paper we assume that we can neglect these big differences in surface moisture due to the facts that this site is quite flat and not in the direct vicinity of a river or glacier melting water outflow. Therefore in our opinion the use of the HMA is possible regarding the influence of heterogeneities in surface moisture. However, the determination of the surface temperature via an infrared sensor could be an uncertainty factor in the flux calculations via HMA. It is just a measurement at one point of a (in our case) quite heterogeneous tundra surface, where grass, moss, bare soil, and little stones (with different colours and therefore different longwave emissivities) are alternating on really small distances. The possible deviation caused by the infrared sensor is unfortunately not to quantify, therefore the exact point on the surface for each surface temperature measurement has to be known, which is not possible with such a high spatial heterogeneity of surface characteristics.

In any case it is highly recommended to investigate these issues on site, variations for different measurement sites in different climatic conditions are most probable.
Outside the convective period the correlation between the eddy covariance method and the hydrodynamic model approach is very low (compare Figures 3(e) to $3(\mathrm{~h})$ ), so no reliable statements are possible about the behaviour of the molecular temperature boundary layer by comparing the eddy covariance and the HMA values.

3.3.2. Further Application Possibilities of the HMA. The simple and reliable HMA provides some possible further applications. First of all the HMA can be easily applied for all eddy covariance systems and provide flux values that are not such dependent from the existence of fully developed turbulence like the eddy covariance method (but note that the layer structure of the lowermost meters over the surface can vary for different measurement sites, compare Section 3.3.1). This layer structure is the probable reason for our discrepancy in fluxes during stable conditions by the different methods eddy covariance and HMA. Especially during stable conditions the HMA provides information distinct from the eddy covariance method (in addition to the turbulent exchange laminar processes are also included in the results of the HMA) and considers thereby, contrary to bulk methods, the layered structure of the near-surface boundary layer.

Moreover, the conditional equation for the sensible heat flux can be rewritten to obtain the surface temperature 


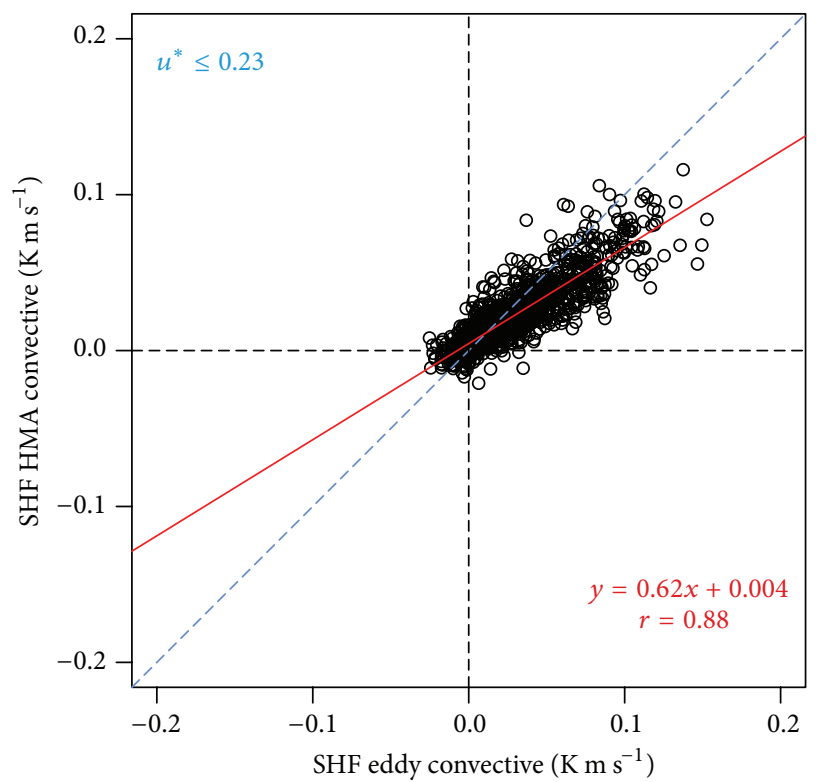

(a)

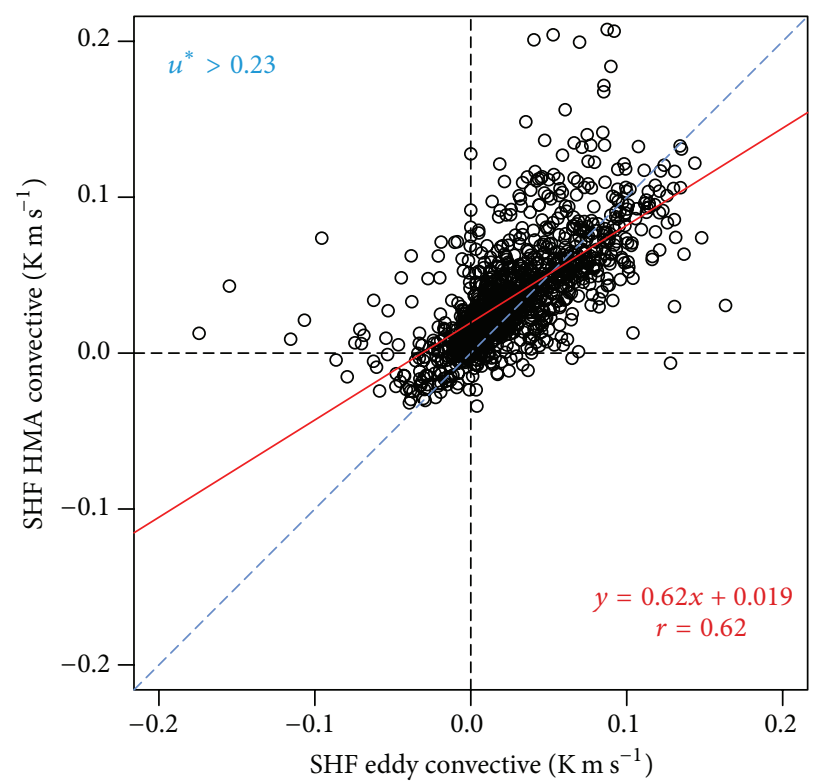

(b)

Figure 7: (a) $30 \mathrm{~min}$ averages of the kinematic sensible heat flux $\left(\mathrm{K} \mathrm{m} \mathrm{s}^{-1}\right)$, eddy covariance versus HMA (with adapted (4)), for the time window 16.6. to 31.8. and friction velocities $\leq 0.23 \mathrm{~m} \mathrm{~s}^{-1}$. Additionally shown is the correlation coefficient between the two data series and the linear regression (line and equation). (b) 30 min averages of the kinematic sensible heat flux ( $\mathrm{K} \mathrm{m} \mathrm{s}^{-1}$ ), eddy covariance versus HMA (with adapted (4)), for the time window 16.6. to 31.8. and friction velocities $>0.23 \mathrm{~m} \mathrm{~s}^{-1}$. Additionally shown is the correlation coefficient between the two data series and the linear regression (line and equation).

according to (7) $[12,29]$. Hence, in climate models where the surface temperature is prescribed the HMA might be used to constrain this important parameter. For example, the HMA could be used in a case study for assimilating the fluxes. This might be important, as Jocher [30] showed that measured fluxes in the Arctic during the convective period could not be simulated with the regional climate model HIRHAM5 [40] for the shown Arctic tundra site. It became obvious that a regional climate model is in no way able to reproduce the positive sensible heat fluxes during the convective period at this site due to the bad representation of the surface temperature in the climate model with its coarse resolution.

\subsubsection{Temperature ITC's under Stable Conditions (Using Eddy} Covariance). As mentioned in Section 2.2 the eddy covariance software TK3 uses for the quality flagging system the same temperature ITC parameterisation for the unstable and the stable case. Directly following is the exclusion of many eddy covariance data in the stable case due to not fulfilling the used parameterisation, remaining is just a small corridor of values fluctuating around zero (see Section 3.1). The actual recommendation by the original authors of TK3 is to completely switch off the temperature ITC's for the flagging system in the case of stable stratification and only use the steady state flag for the overall flag (see also Table 1).

In the following the topic of the temperature ITC's shall be discussed further by presenting corresponding data of the investigation period which is shown in this paper. Figure 8 shows the absolute values of the temperature ITC's (calculated following formulas (2) and (3)) for the convective period (16.6.-31.8.) and the rest of the shown year (1.9.-15.6., not convective) in dependency of the dimensionless stability parameter $z / L$. Additionally shown in Figure 8 are the absolute values of the hyperbolic cotangent of the values of $z / L$ and the temperature ITC's following the parameterisation of Foken et al. [27].

Several things are obvious in Figure 8: first we see that the stratification for the convective period is more or less always unstable or neutral and the absolute values for the temperature ITC's are besides some exceptions continuously lower than the corresponding absolute values of the hyperbolic cotangent of the values of $z / L$.

Next it is well to see that in the not convective period a quite huge amount of negative values of $z / L$ are generated, which indicates unstable stratification. These values are to explain by the already discussed effect of fictitious positive sensible heat fluxes generated by the eddy covariance method in the case of external gravity waves, a case in which the eddy covariance method fails. The temperature ITC's in these cases are not well defined and strongly scattering outside the range of the absolute values of the hyperbolic cotangent of the values of $z / L$.

Furthermore it is obvious that the lower limit of the temperature ITC's is rising with the stability values and the more stable the stratification is the more are the temperature ITC's scattering. For $z / L$ values higher than 0.4 the absolute values of temperature ITC's are continuously higher than the absolute values of the hyperbolic cotangent of the values of $z / L$. 


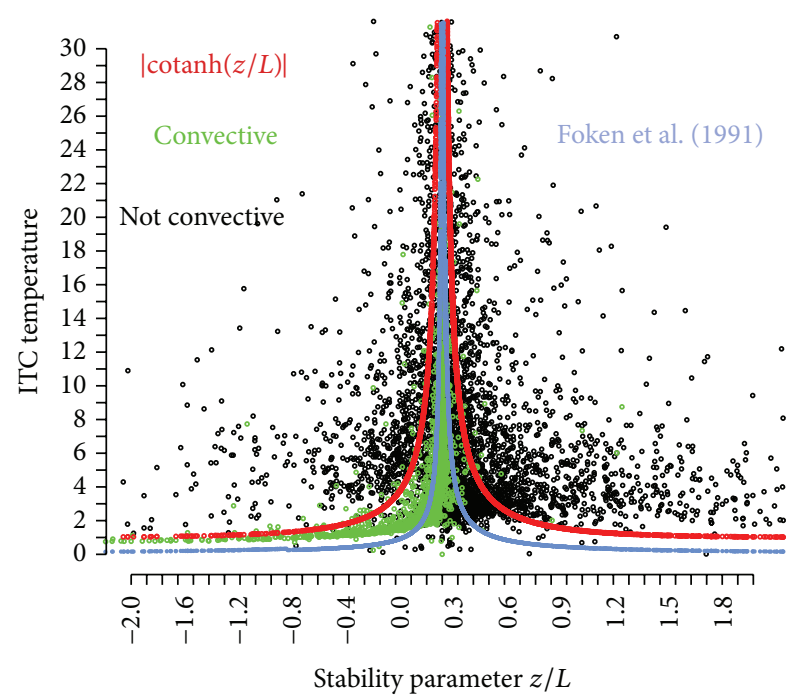

FIGURE 8: Absolute values of the temperature ITC's (calculated following formulas (2) and (3)) for the convective period (16.6.31.8., green dots) and the rest of the shown year (1.9.-15.6., not convective, black dots) in dependency of the stability parameter $z / L$. Additionally shown are the absolute values of the hyperbolic cotangent of the values of $z / L$ (red dots) and the temperature ITC's following the parameterisation of Foken et al. ([27], blue crosses).

Taking the temperature ITC's in the convective period as a reference (in Section 3 it was discussed that the general sensible heat flux behaviour in the convective period does not differ substantially between all flux values and the flux values for the actual sensible heat flux quality flag 1-3 in TK3) we can now formulate a new temperature ITC quality criterion for the stability range unstable (negative $z / L$ values) up to $z / L=0.4$ (excluding $z / L=0$, the hyperbolic cotangent is not defined there): usable are all sensible heat flux values fulfilling the condition

$$
\left|\mathrm{ITC}_{T}\right| \leq\left|\operatorname{cotanh}\left(\frac{z}{L}\right)\right|
$$

The stability range $z / L>0.4$ needs a separate handling. Turbulence in this stability range is damped, often intermittent or generated by breaking waves and so more difficult to detect and analyze than outside this stability range. Under such circumstances one main precondition of the eddy covariance method, namely, well-developed turbulence over the whole flux calculation averaging time, is not fulfilled. This fact explains the large scattering of the temperature ITC-values in this stability range.

A few more words to the motivation of this criterion: seeking an exclusion criterion for the sensible heat fluxes at the shown Arctic tundra site (just the decision: accept or refuse) which is applicable for an as wide as possible stability range the correlation in (9) was found as an elegant way to do this. The form (but not the formula) of this criterion is similar to already existing criteria like the one proposed by Foken et al. [27] which is additionally drawn in Figure 8. For the sake of completeness at this point it has to be said that we assumed a not existing displacement height for the parameterisations following Foken et al. [27] due to a not existing canopy at the measurement site. This assumption is possibly not fully fulfilled and may lead to a small underestimation of the in Figure 8 shown parameterisations following Foken et al. [27], but the main conclusions of Figure 8 are unaffected by this.

In difference to already existing criteria (like the one by Foken et al. [27]), which are prediction parameterisations trying to model the ITC's in the best way, mostly using different parameterisations for different stability ranges, we propose here an exclusion criterion with a unique form for the whole stability range. The proposed criterion (9) gives the possibility to transfer the precondition well-developed turbulence (one of the major preconditions for the meaningful use of the eddy covariance method) from the unstable stability range also on the neutral and stable stability range (up to $z / L=0.4$ ).

\section{Conclusions}

In the previous sections the near-surface sensible heat flux behaviour (obtained by the eddy covariance method and a hydrodynamic model approach (HMA)) in the course of the year was presented for an Arctic measurement site near Ny-Ålesund, Spitsbergen. It became clear that the behaviour of the near-surface sensible heat flux strongly depends on season, wind direction, and friction velocity. Taking all shown results into account, especially the results in the "disturbed" sector (wind direction $150^{\circ}-270^{\circ}$ ) should be handled carefully, in this sector mountains and glaciers in the direct vicinity of the eddy covariance measurement complex lead to many disturbances. The recommendation at this point is to exclude the flux values which were obtained during flow from the mentioned sector, if possible. If not possible, filter techniques (like wavelet for example; compare, e.g., [41]) or the use of quality flags can help to exclude the fictitious positive sensible heat flux values, which are generated by external gravity waves using the eddy covariance method. Table 2 summarizes the most important results in a table with additional remarks.

Some thoughts to the use of the eddy covariance method on the one side and gradient approaches (including the introduced hydrodynamic model approach as a special case) on the other side regarding their application at Arctic measurement sites shall be inserted at this point: the eddy covariance method determines the turbulent fluxes, gradient approaches turbulent and laminar exchange due to their use of the temperature gradient between a defined measurement height and the surface. Both methods fit quite well together if we can assume the turbulent exchange as dominant process (we saw that in this paper for the convective period). Indeed, the performance of the two methods differs clearly during polar night conditions if turbulence is damped and/or only intermittent. Quite large negative fluxes using gradient approaches (which represent turbulent and molecular exchange) are then standing against fluxes mainly fluctuating around zero using the eddy covariance method (which represent only the turbulent flux), the gradient approaches are "too stable" regarding the turbulent exchange. This difference is fostered by clear sky conditions and low wind velocities, which means 


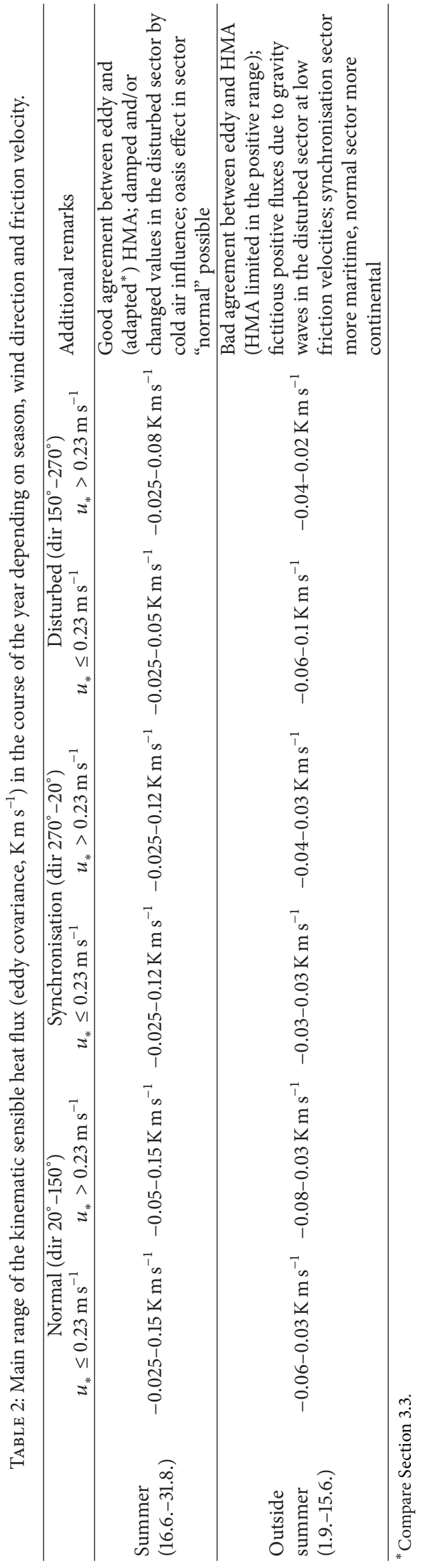


a strong longwave radiative loss (and therefore big temperature differences between measurement height and surface) and damped mixing due to low friction. Cloudy conditions and/or higher friction velocities limit the formation of a strong temperature gradient between measurement height and surface and therefore the laminar exchange. What could now be a potential application of this knowledge? It should be possible to make severe statements about the development of turbulence in the course of the whole year by comparing results of the eddy covariance method (determines turbulent flux) and results of the hydrodynamic model approach (determines turbulent flux and laminar flux). By doing this a kind of critical value of turbulence development could be defined up to which it makes sense to compare eddy covariance results and hydrodynamic model results in special (but also model results in general) as equal methods for turbulent flux determination. Precondition for that: the knowledge of the structure of the undermost meters of the atmosphere. Investigations about the thickness of the molecular boundary layer should be done at each measurement site before providing further investigations.

To verify this idea, further work is needed and ongoing. Indeed, the hydrodynamic model approach used in this paper would be an ideal tool for such investigations due to its possibility to resolve the layer structure and the corresponding processes in the lowermost meters of the atmosphere exactly and physically well-founded, a clear advantage of the HMA comparing to other gradient approaches.

\section{Conflict of Interests}

The authors declare that there is no conflict of interests regarding the publication of this paper.

\section{Acknowledgments}

Many thanks go to Jürgen Graeser, AWI Potsdam, for technical support regarding the installation of the instruments mentioned in this paper and the AWIPEV Crew for the routine checks and maintenance work to keep the instruments running on site.

\section{References}

[1] M. C. Serreze and R. G. Barry, "Processes and impacts of Arctic amplification: a research synthesis," Global and Planetary Change, vol. 77, no. 1-2, pp. 85-96, 2011.

[2] F. Pithan and T. Mauritsen, "Arctic amplification dominated by temperature feedbacks in contemporary climate models," Nature Geoscience Letters, vol. 7, pp. 181-184, 2014.

[3] J. A. Screen and I. Simmonds, "Increasing fall-winter energy loss from the Arctic Ocean and its role in Arctic temperature amplification," Geophysical Research Letters, vol. 37, no. 16, 2010.

[4] J. E. Kay, K. Raeder, A. Gettelman, and J. Anderson, "The boundary layer response to recent arctic sea ice loss and implications for high-latitude climate feedbacks," Journal of Climate, vol. 24, no. 2, pp. 428-447, 2011.
[5] M. Tjernström, M. Žagar, G. Svensson et al., "Modelling the Arctic boundary layer: an evaluation of six ARCMIP regionalscale models using data from the SHEBA project," BoundaryLayer Meteorology, vol. 117, no. 2, pp. 337-381, 2005.

[6] B. Medeiros, C. Deser, R. A. Tomas, and J. E. Kay, "Arctic inversion strength in climate models," Journal of Climate, vol. 24, no. 17, pp. 4733-4740, 2011.

[7] E. Mäkiranta, T. Vihma, A. Sjöblom, and E.-M. Tastula, "Observations and modelling of the atmospheric boundary layer over sea-ice in a Svalbard Fjord," Boundary-Layer Meteorology, vol. 140, no. 1, pp. 105-123, 2011.

[8] A. S. Monin and A. M. Obukhov, "Osnovnye zakonomernosti turbulentnogo peremeshivanija $\mathrm{v}$ prizemnom sloe atmosfery (basic laws of turbulent mixing in the atmosphere near the ground)," Trudy Geofizicheskogo Instituta, Akademiya Nauk SSSR, vol. 24, no. 151, pp. 163-187, 1954.

[9] D. Handorf, T. Foken, and C. Kottmeier, "The stable atmospheric boundary layer over an antarctic ice sheet," BoundaryLayer Meteorology, vol. 91, no. 2, pp. 165-189, 1999.

[10] M. Aubinet, T. Vesala, and D. Papale, Eddy Covariance: A Practical Guide to Measurement and Data Analysis, Springer, London, UK, 2012.

[11] G. Jocher, F. Karner, C. Ritter et al., "The near-surface smallscale spatial and temporal variability of sensible and latent heat exchange in the Svalbard region: a case study," ISRN Meteorology, vol. 2012, Article ID 357925, 14 pages, 2012.

[12] J. Lüers and J. Bareiss, "The effect of misleading surface temperature estimations on the sensible heat fluxes at a high Arctic site-the arctic turbulence experiment 2006 on Svalbard (ARCTEX-2006)," Atmospheric Chemistry and Physics, vol. 10, no. 1, pp. 157-168, 2010.

[13] S. Westermann, J. Lüers, M. Langer, K. Piel, and J. Boike, “The annual surface energy budget of a high-arctic permafrost site on Svalbard, Norway," Cryosphere, vol. 3, no. 2, pp. 245-263, 2009.

[14] T. Foken, "Vorschlag eines verbesserten Energieaustauschmodells mit Berücksichtigung der molekularen Grenzschicht der Atmosphäre," Meteorologische Zeitschrift, vol. 29, pp. 32-39, 1979.

[15] T. Foken, "The parameterisation of the energy exchange across the air-sea interface," Dynamics of Atmospheres and Oceans, vol. 8, no. 3-4, pp. 297-305, 1984.

[16] M. Maturilli, A. Herber, and G. König-Langlo, "Climatology and time series of surface meteorology in Ny-Ålesund, Svalbard," Earth System Science Data, vol. 5, pp. 155-163, 2013.

[17] J. A. Businger, "Evaluation of the accuracy with which dry deposition can be measured with current micrometeorological techniques," Journal of Climate \& Applied Meteorology, vol. 25, no. 8, pp. 1100-1124, 1986.

[18] D. H. Haugen, Ed., Workshop on Micrometeorology, American Meteorological Society, Boston, Mass, USA, 1973.

[19] J. C. Kaimal and J. J. Finnigan, Atmospheric Boundary Layer Flows: Their Structure and Measurement, Oxford University Press, New York, NY, USA, 1994.

[20] X. Lee, W. J. Massman, and B. Law, Eds., Handbook of Micrometeorolgy: A Guide for Surface Flux Measurements and Analysis, Kluwer Academic Publishers, Dordrecht, The Netherlands, 2004.

[21] G. Fratini and M. Mauder, "Towards a consistent eddycovariance processing: an intercomparison of EddyPro and TK3," Atmospheric Measurement Techniques, vol. 7, pp. 22732281, 2014. 
[22] M. Mauder and T. Foken, Documentation and Instruction Manual of the Eddy Covariance Software Package TK3, vol. 46, Arbeitsergebnisse Universität Bayreuth, Abteilung Mikrometeorologie, Bayreuth, Germany, 2011.

[23] M. Mauder, T. Foken, R. Clement et al., "Quality control of CarboEurope flux data-part 2: inter-comparison of eddycovariance software," Biogeosciences, vol. 5, no. 2, pp. 451-462, 2008.

[24] T. Foken, M. Göckede, M. Mauder, L. Mahrt, B. D. Amiro, and W. J. Munger, "Post-field data quality control," in Handbook of Micrometeorology: A Guide for Surface Flux Measurements and Analysis, X. Lee, W. J. Massmann, and B. Law, Eds., pp. 181-208, Kluwer, Dordrecht, The Netherlands, 2004.

[25] T. Foken, R. Leuning, S. P. Oncley, M. Mauder, and M. Aubinet, "Corrections and data quality control," in Eddy Covariance: A Practical Guide to Measurement and Data Analysis, M. Aubinet, T. Vesala, and D. Papale, Eds., Springer Atmospheric Sciences, pp. 85-131, Springer, Dordrecht, The Netherlands, 2012.

[26] T. Foken and B. Wichura, "Tools for quality assessment of surface-based flux measurements," Agricultural and Forest Meteorology, vol. 78, no. 1-2, pp. 83-105, 1996.

[27] T. Foken, G. Skeib, and S. H. Richter, "Dependence of the integral turbulence characteristics on the stability of stratification and their use for Doppler-Sodar measurements," Meteorologische Zeitschrift, vol. 41, pp. 311-315, 1991.

[28] C. Thomas and T. Foken, "Re-evaluation of integral turbulence characteristics and their parameterisations," in Proceedings of the 15th Conference on Turbulence and Boundary Layers, pp. 129-132, American Meteorological Society, Wageningen, The Netherlands, July 2002.

[29] H. Sodemann and T. Foken, "Special characteristics of the temperature structure near the surface," Theoretical and Applied Climatology, vol. 80, no. 2-4, pp. 81-89, 2005.

[30] G. Jocher, Charakterisierung der arktischen bodennahen Turbulenz unter Verwendung verschiedener Methoden der Flussberechnung und daraus resultierende Möglichkeiten für die Berechnung der bodennahen turbulenten Flüsse im regionalen Klimamodell HIRHAM5 [Ph.D. thesis], University of Potsdam, Institute for Physics and Astronomy, Potsdam, Germany, 2013.

[31] J. A. Businger, J. C. Wyngaard, Y. Izumi, and E. F. Bradley, "Fluxprofile relationships in the atmospheric surface layer," Journal of the Atmospheric Sciences, vol. 28, no. 2, pp. 181-189, 1971.

[32] G. Skeib, "Zur Definition universeller Funktionen für die Gradienten von Windgeschwindigkeit und Temperatur in der bodennahen Luftschicht," Meteorologische Zeitschrift, vol. 30, pp. 23-32, 1980.

[33] U. H and U. Högström, "Non-dimensional wind and temperature profiles in the atmospheric surface layer: a re-evaluation," Boundary-Layer Meteorology, vol. 42, no. 1-2, pp. 55-78, 1988.

[34] A. M. Obukhov, “Turbulentnost'v temperaturnoj-neo dnorodnoj atmosphere (turbulence in an atmosphere with a nonuniform temperature," Trudy Instituta Teoreticheskio Geofiziki AN SSSR, vol. 1, pp. 95-115, 1946.

[35] A. M. Obukhov, "Turbulence in an atmosphere with a nonuniform temperature," Boundary-Layer Meteorology, vol. 2, no. 1, pp. 7-29, 1971.

[36] T. Foken, "The molecular temperature boundary layer of the atmosphere over various surfaces," Archiv für Meteorologie, Geophysik und Bioklimatologie A, vol. 27, no. 1, pp. 59-67, 1978.

[37] H. J. Beine, S. Argentini, A. Maurizi, G. Mastrantonio, and A. Viola, "The local wind field at Ny-Ålesund and the Zeppelin mountain at svalbard," Meteorology and Atmospheric Physics, vol. 78, no. 1-2, pp. 107-113, 2001.

[38] T. Foken, S. A. Kitajgorodskij, and O. A. Kuznecov, "On the dynamics of the molecular temperature boundary layer above the sea," Boundary-Layer Meteorology, vol. 15, no. 3, pp. 289300, 1978.

[39] S. Westermann, M. Langer, and J. Boike, "Spatial and temporal variations of summer surface temperatures of higharctic tundra on Svalbard-implications for MODIS LST based permafrost monitoring," Remote Sensing of Environment, vol. 115, no. 3, pp. 908-922, 2011.

[40] O. B. Christensen, M. Drews, and J. H. Christensen, "The HIRHAM regional climate model version $5(\beta)$," Tech. Rep. 0617, Danish Meteorological Institute, 2007.

[41] D. Handorf and T. Foken, "Strukturanalyse der atmosphärischen Turbulenz mittels Wavelet-Verfahren zur Bestimmung der Austauschprozesse über dem antarktischen Schelfeis," Deutscher Wetterdienst, Geschäftsbereich Forschung und Entwicklung, vol. 47, pp. 1-49, 1997.

[42] S. Westermann, Sensitivity of permafrost [Ph.D. thesis], Universität Heidelberg, 2010.

[43] T. Foken, Der Bayreuther Turbulenzknecht, vol. 1 of Abteilung Mikrometeorologie, Arbeitsergebnisse Universität Bayreuth, 1999. 

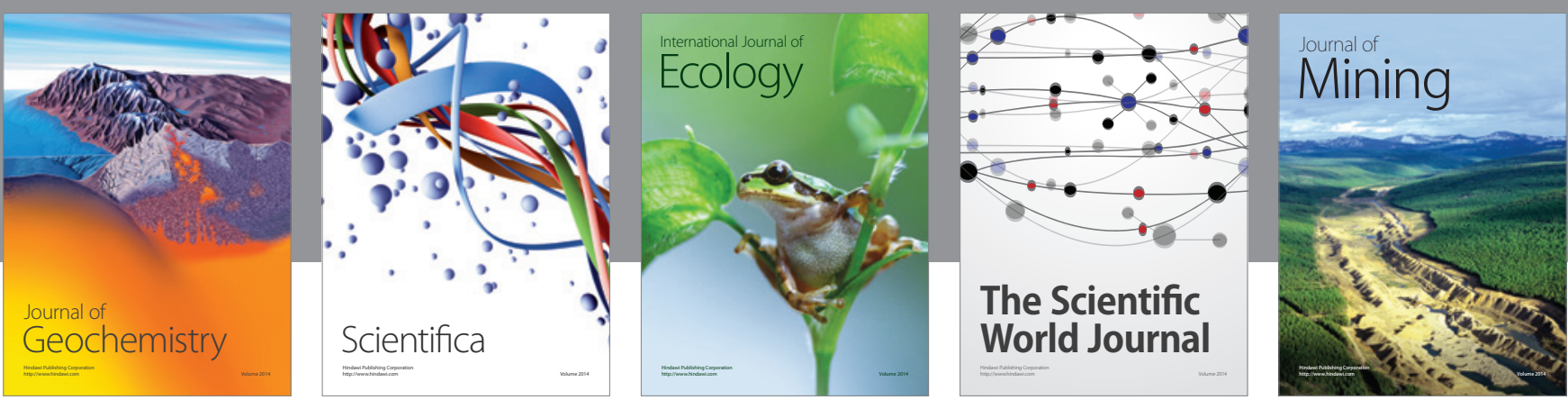

The Scientific World Journal
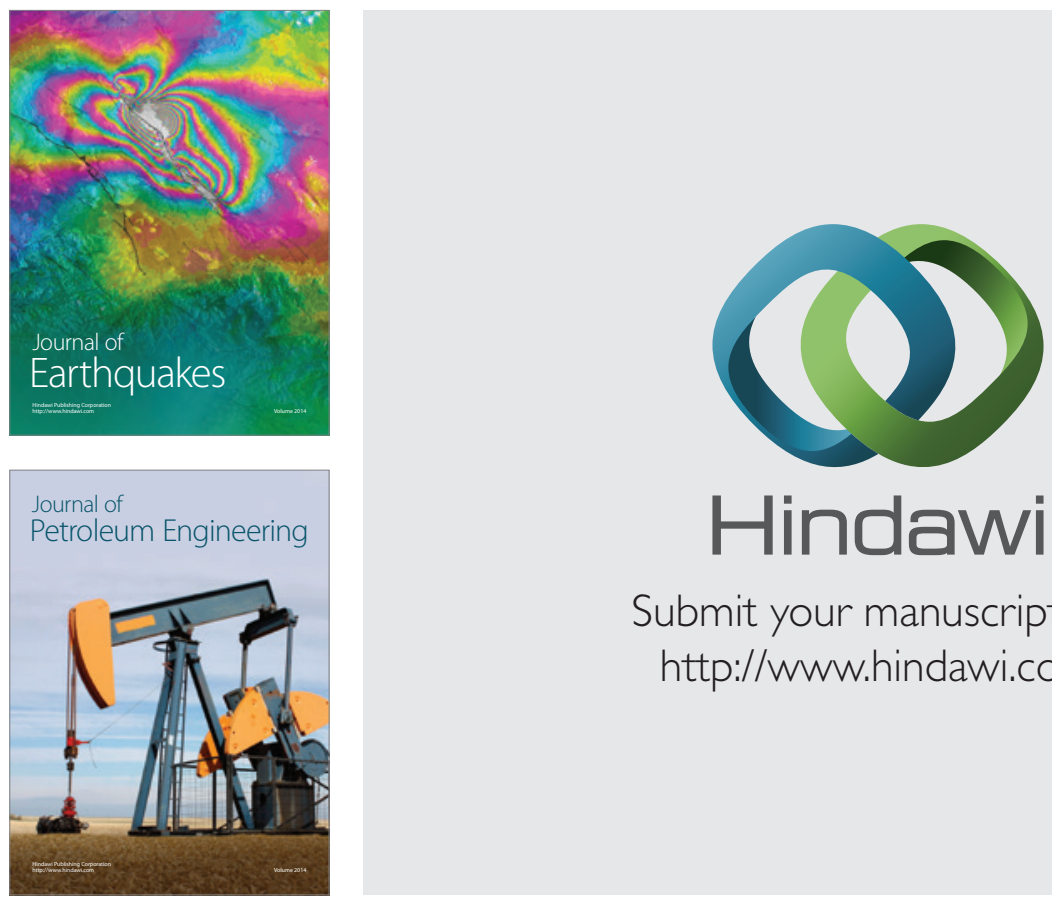

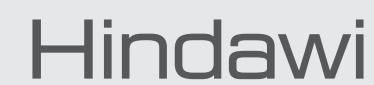

Submit your manuscripts at

http://www.hindawi.com
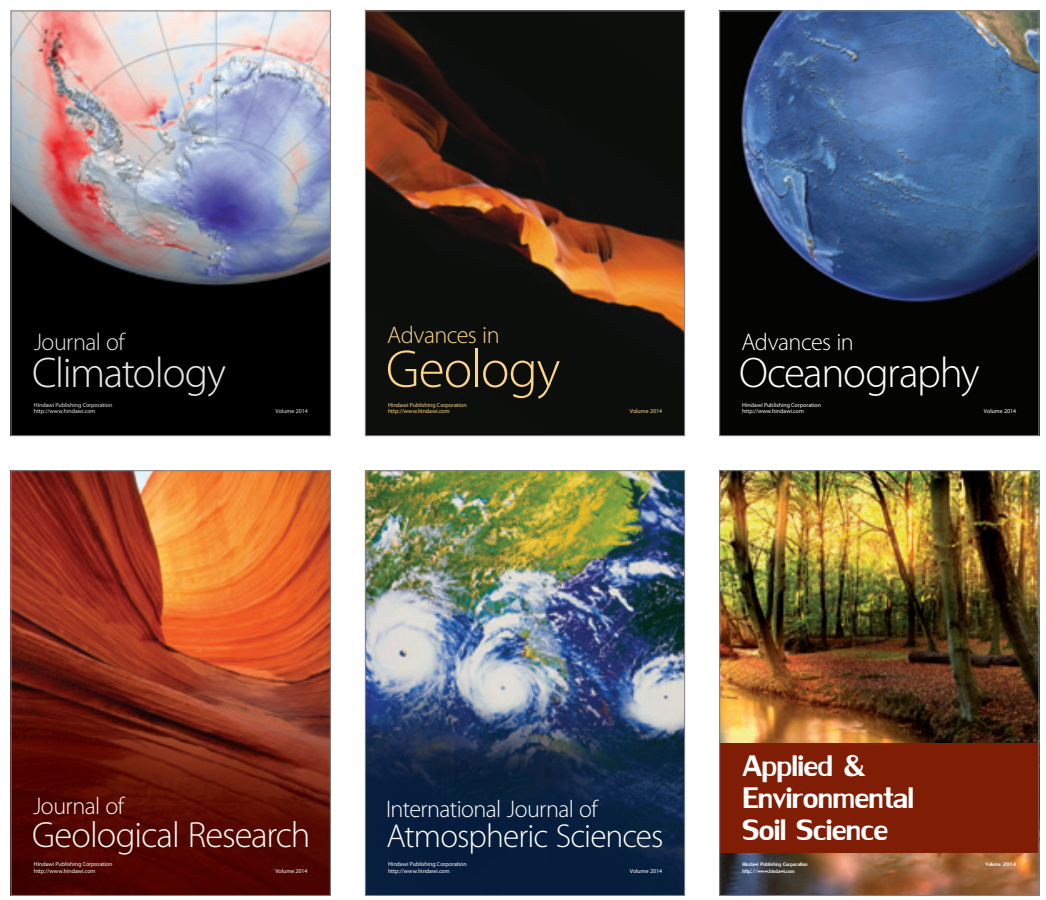
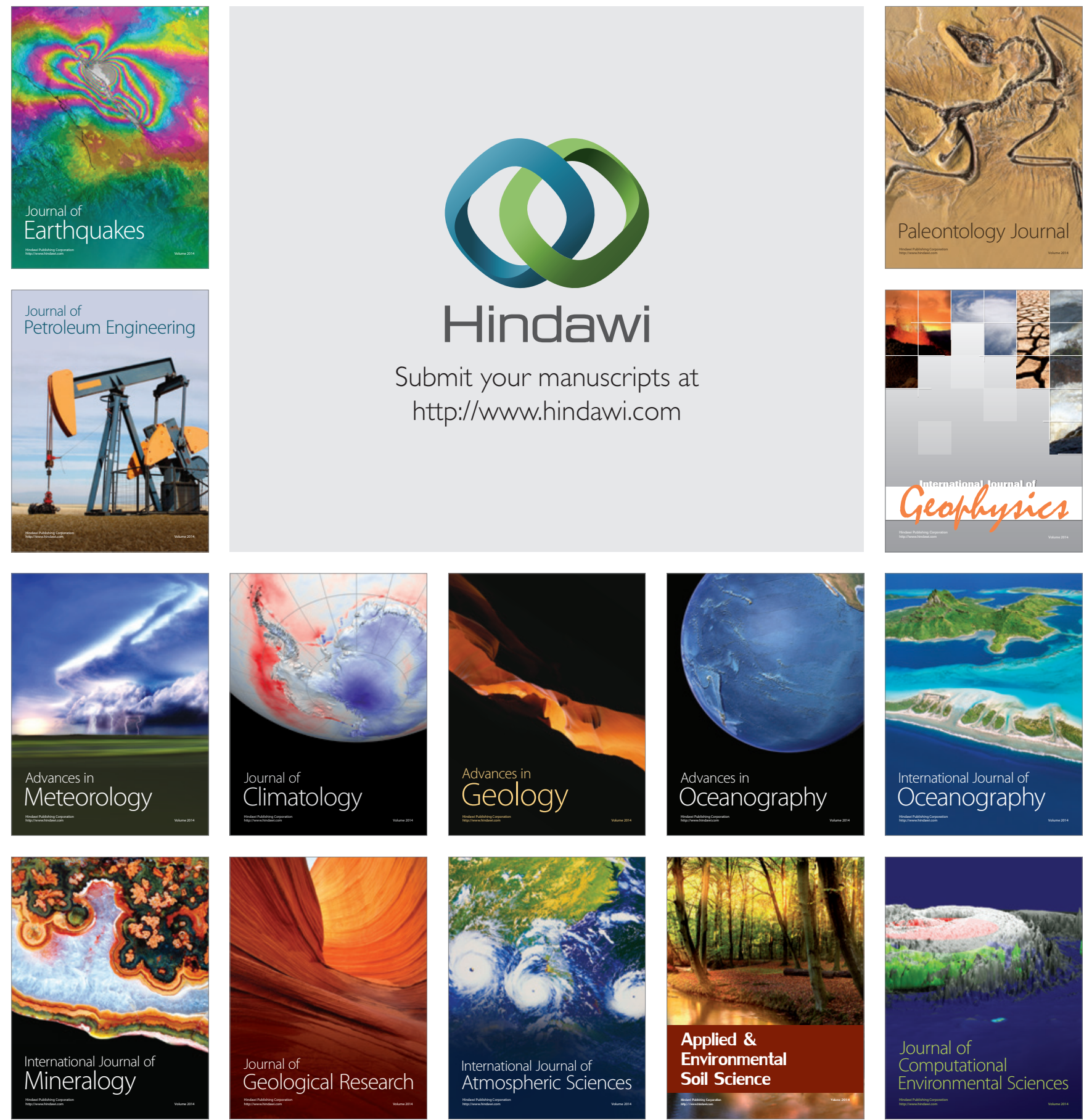